\title{
Novel $S$-thiazol-2-yl-furan-2-carbothioate derivatives as potential T3SS inhibitors against Xanthomonas oryzae on rice
}

\author{
Shan Jiang ${ }^{\dagger, \#}$, Min $\mathrm{He}^{\dagger, \#}$, Xu-Wen Xiang ${ }^{\dagger}$, Muhammad Adnan ${ }^{\dagger}$, Zi-Ning Cui ${ }^{\dagger}, *$
}

†State Key Laboratory for Conservation and Utilization of Subtropical Agro-bioresources, Integrative Microbiology Research Centre, Guangdong Province Key Laboratory of Microbial Signals and Disease Control, South China Agricultural University, Guangzhou 510642, China

\footnotetext{
\#Both authors contributed equally to this paper.

*Corresponding author. Tel.: +86-20-85288229; Fax: +86-20-85288229

E-mail address: ziningcui@scau.edu.cn (Z. C.)
} 


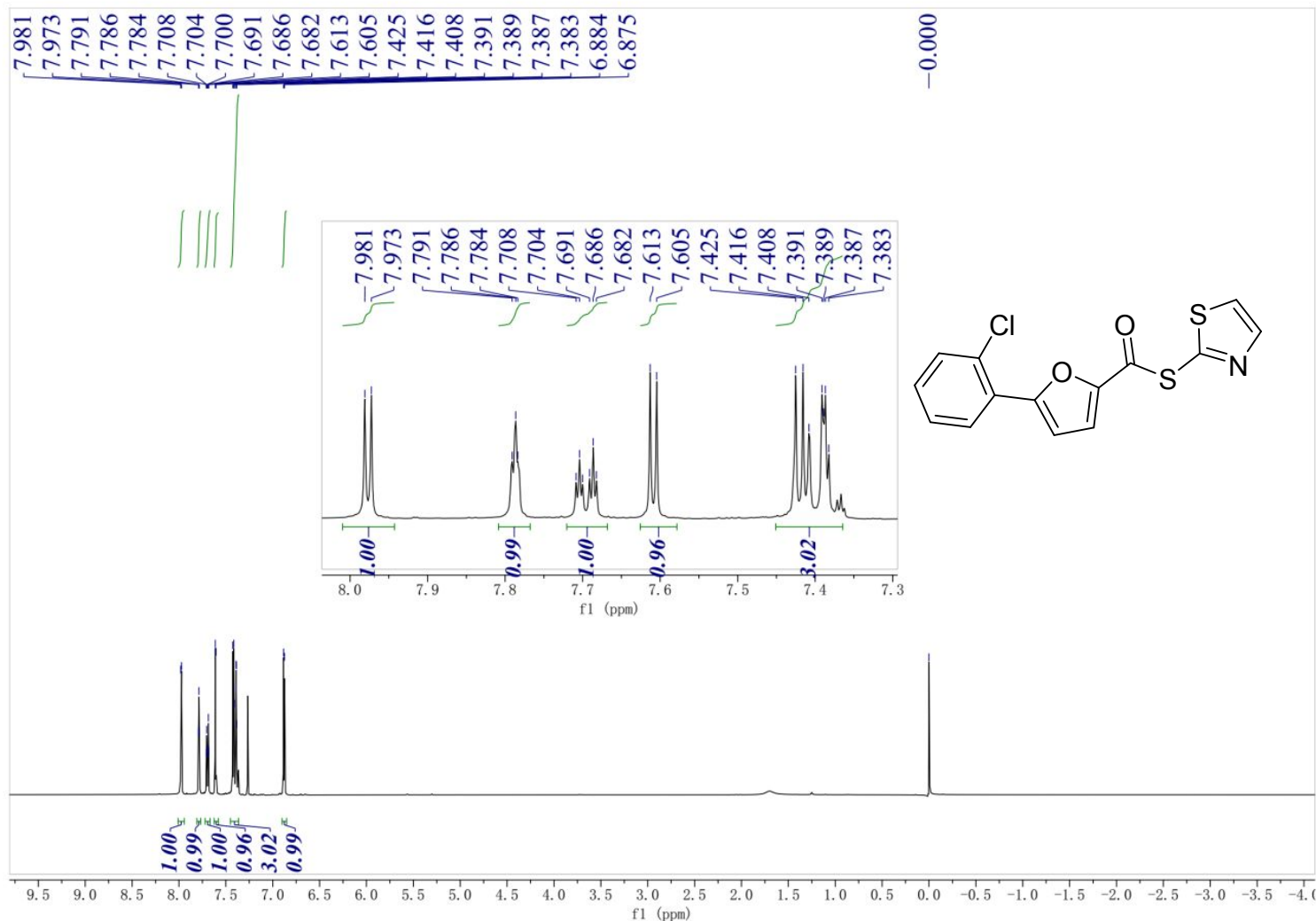

Figure S1 ${ }^{1} \mathrm{H}$ NMR spectrum of compound III-1 


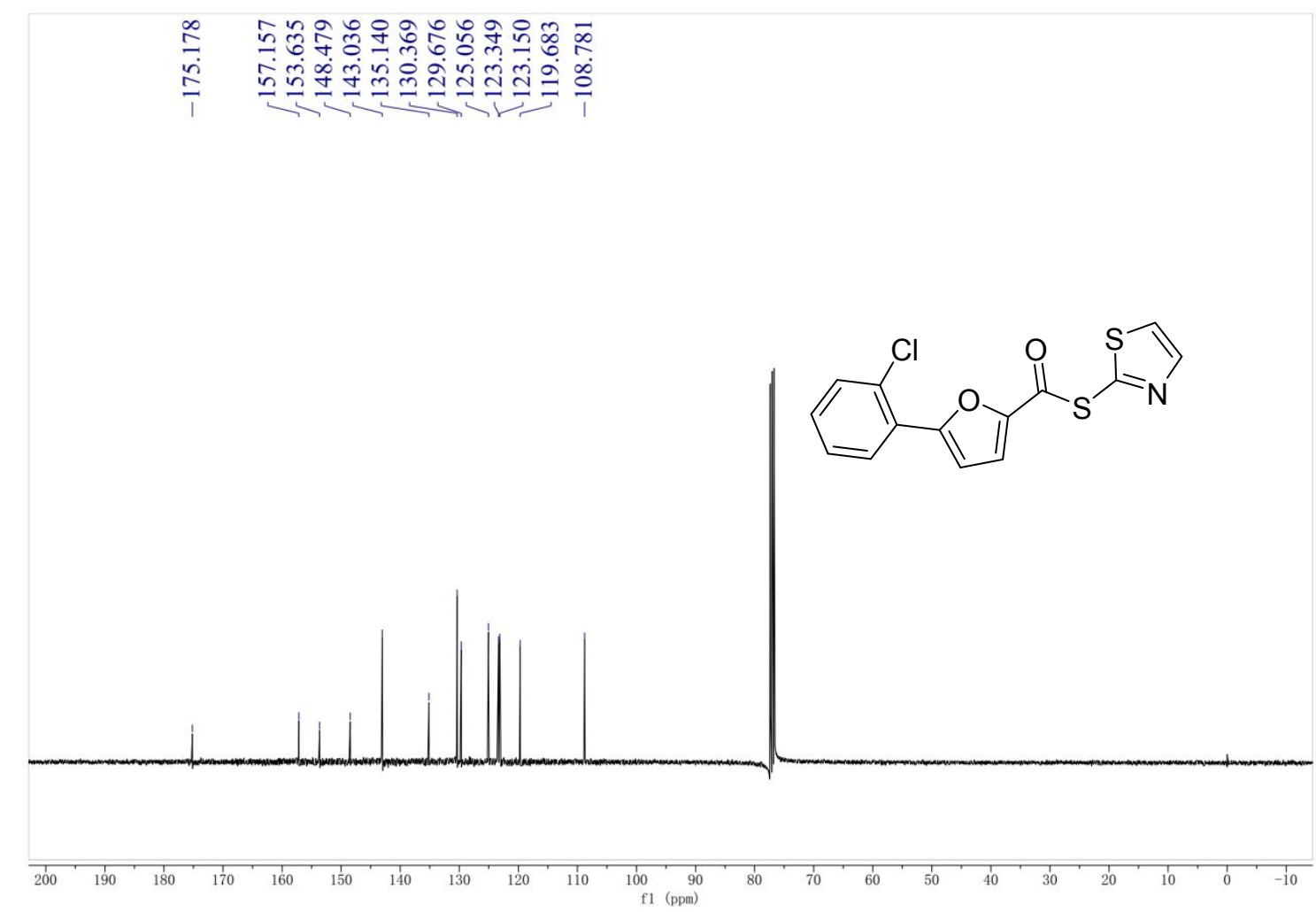

Figure S2 ${ }^{13} \mathrm{C}$ NMR spectrum of compound III-1

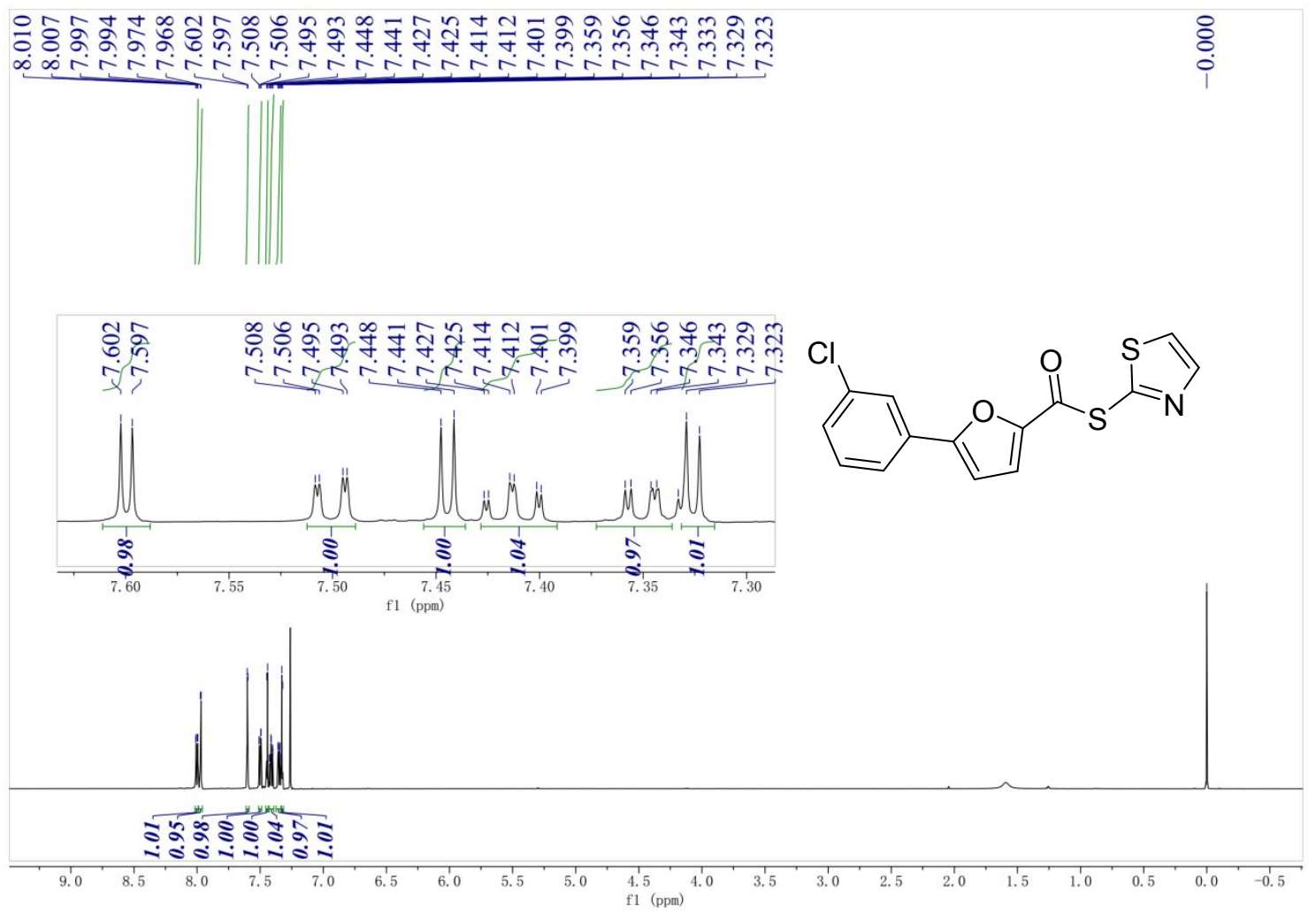

Figure $\mathbf{S 3}{ }^{1} \mathrm{H}$ NMR spectrum of compound III-2 


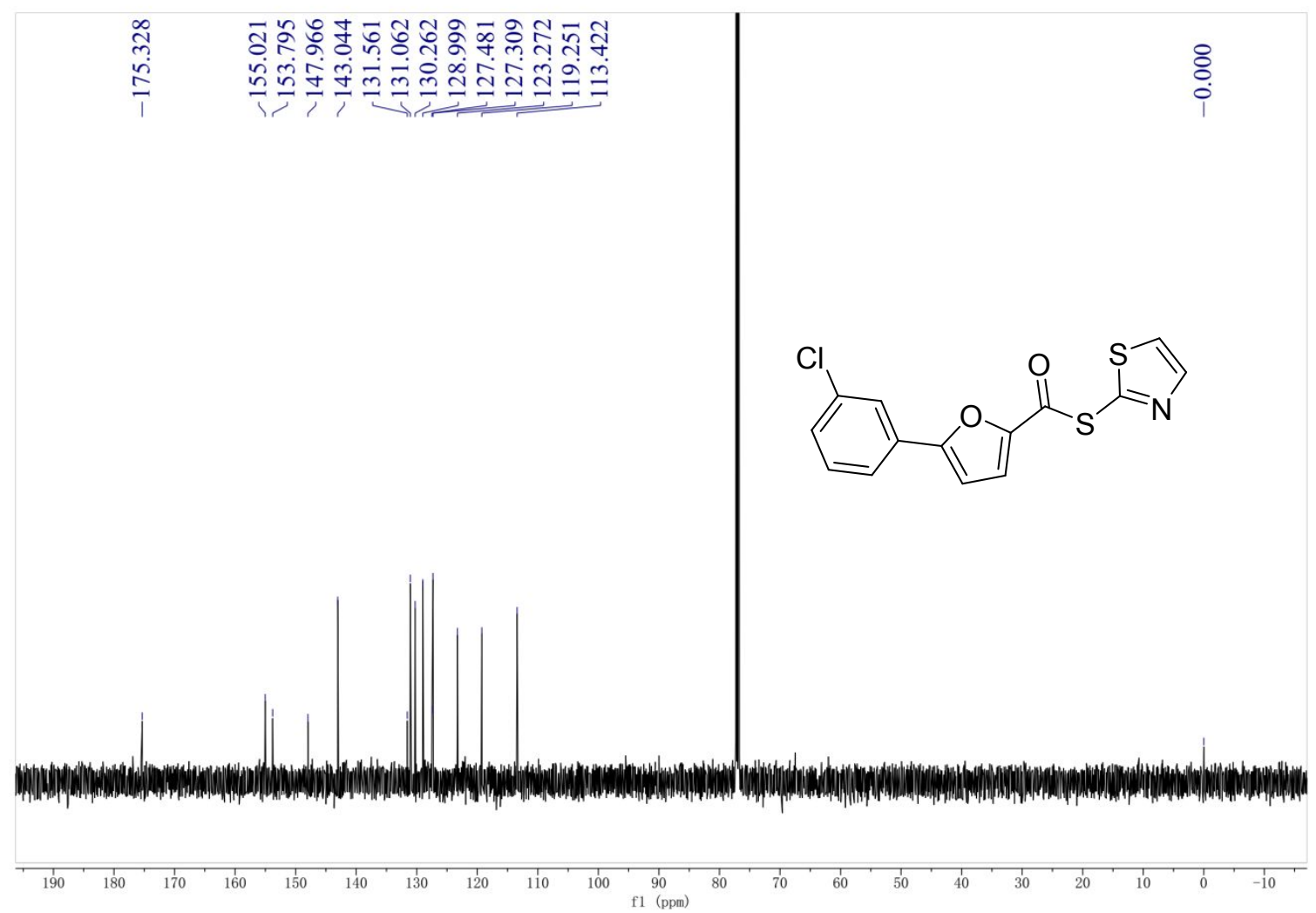

Figure $\mathbf{S 4}{ }^{13} \mathrm{C}$ NMR spectrum of compound III-2

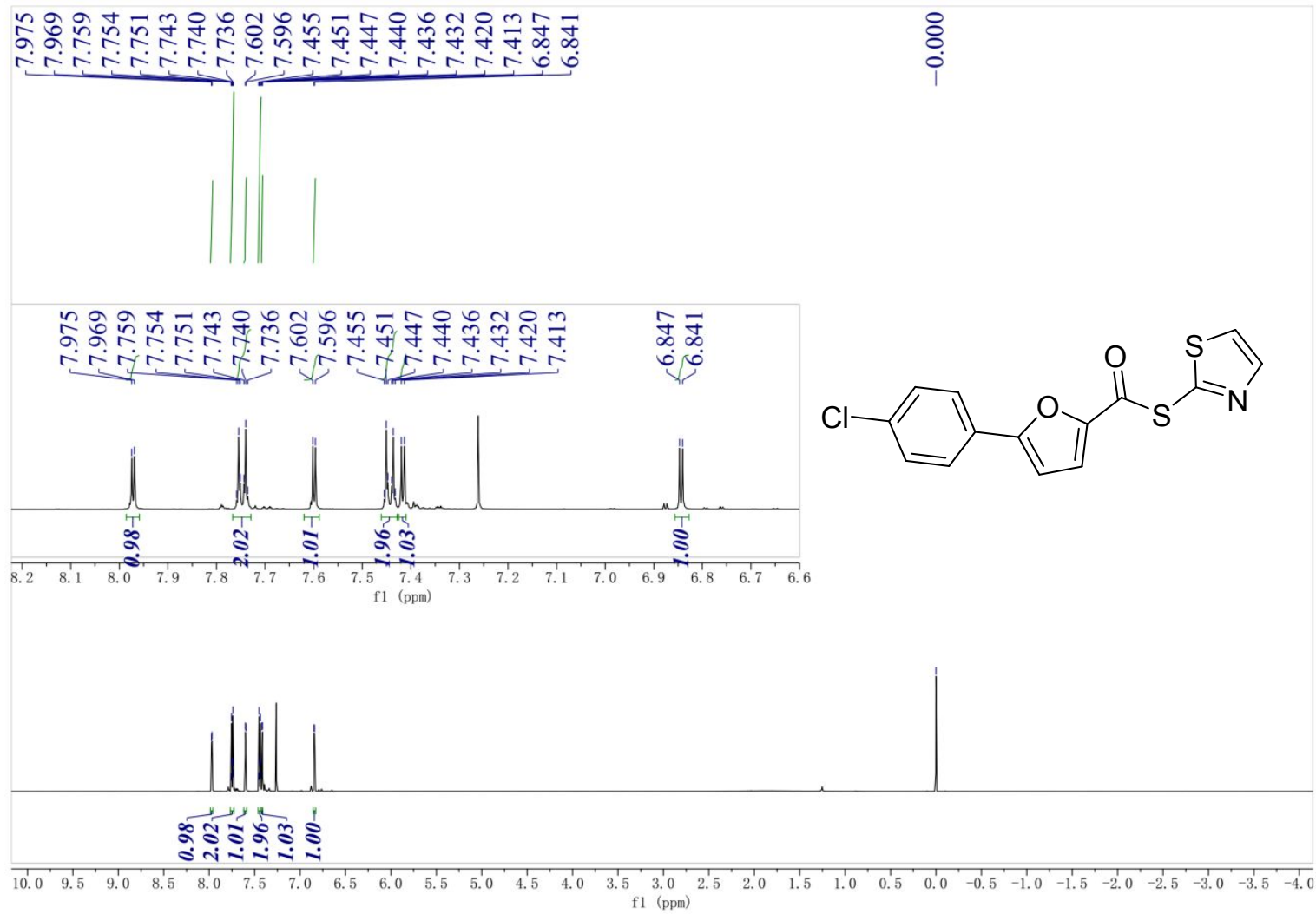

Figure S5 ${ }^{1} \mathrm{H}$ NMR spectrum of compound III-3 


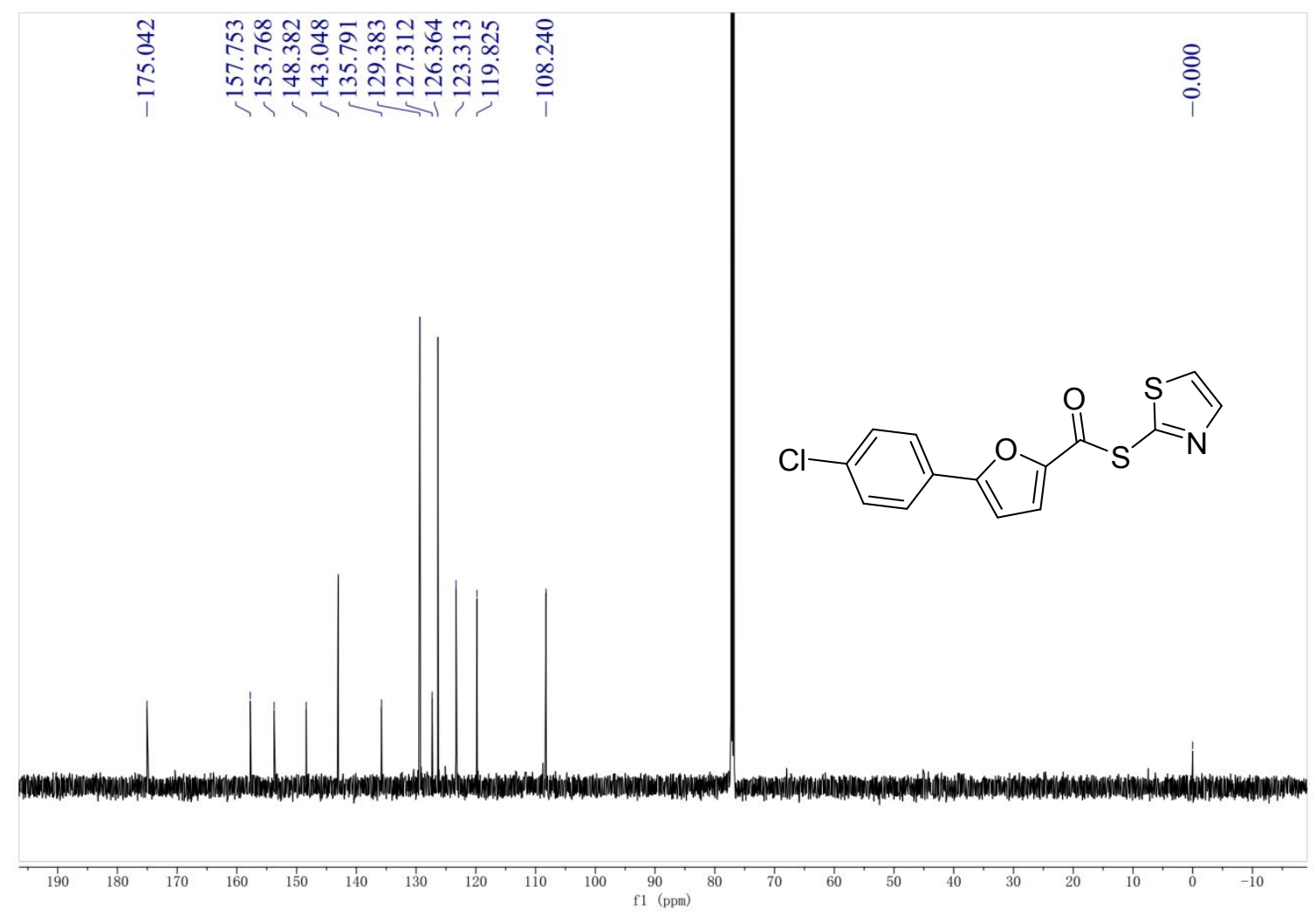

Figure S6 ${ }^{13} \mathrm{C}$ NMR spectrum of compound III-3

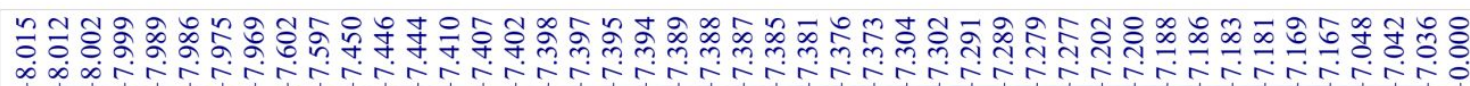

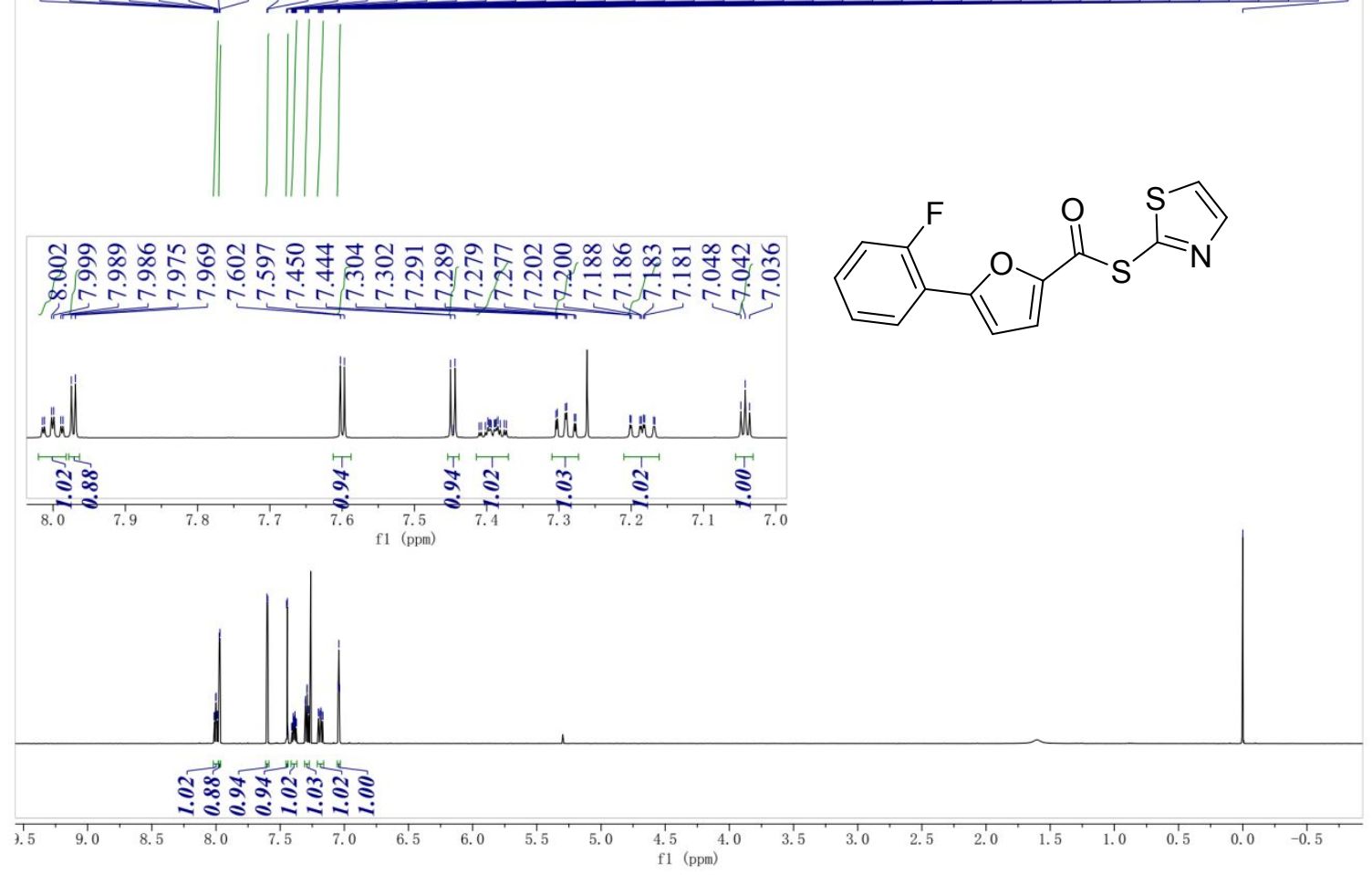

Figure S7 ${ }^{1} \mathrm{H}$ NMR spectrum of compound III-4 


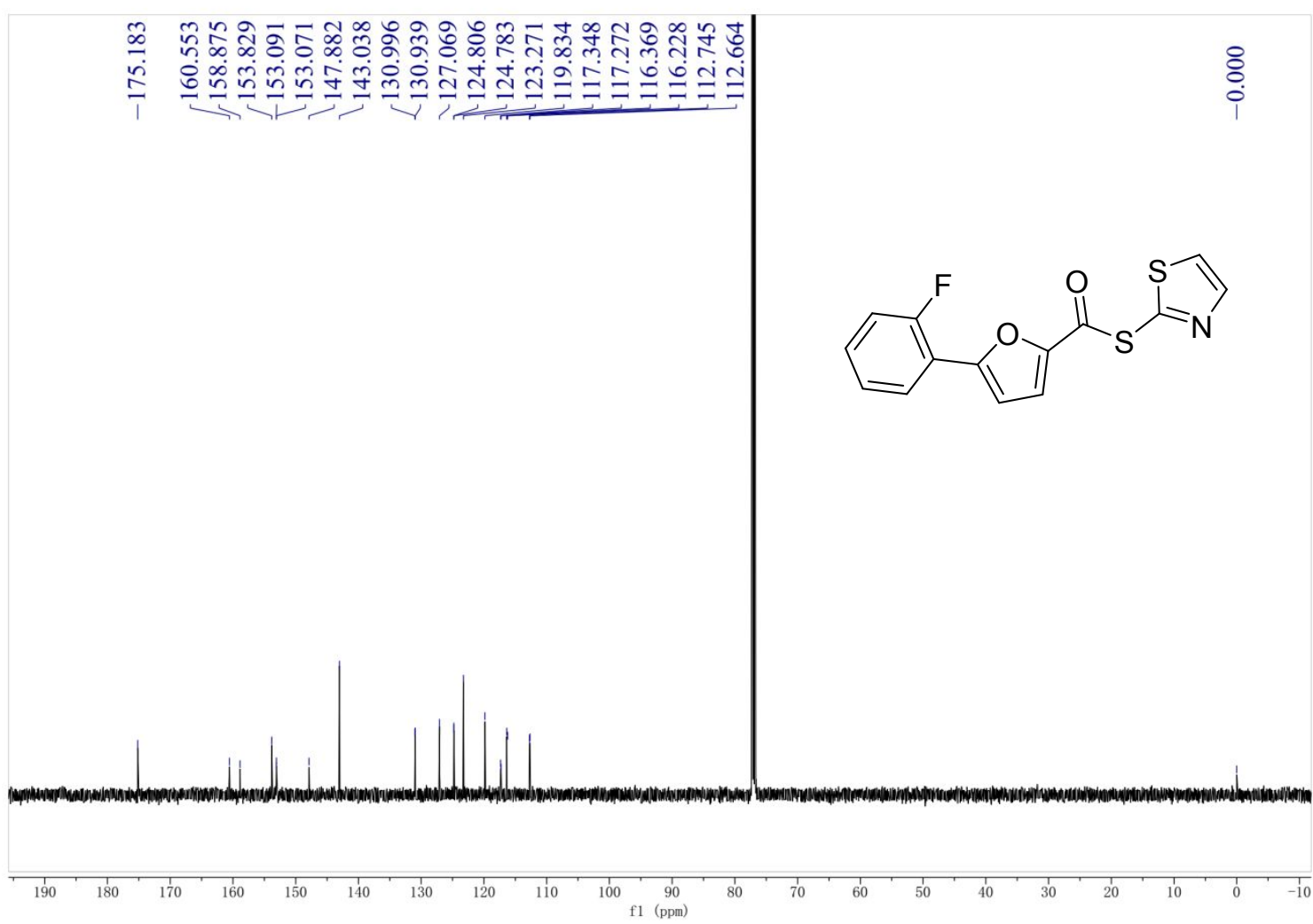

Figure S8 ${ }^{13} \mathrm{C}$ NMR spectrum of compound III-4

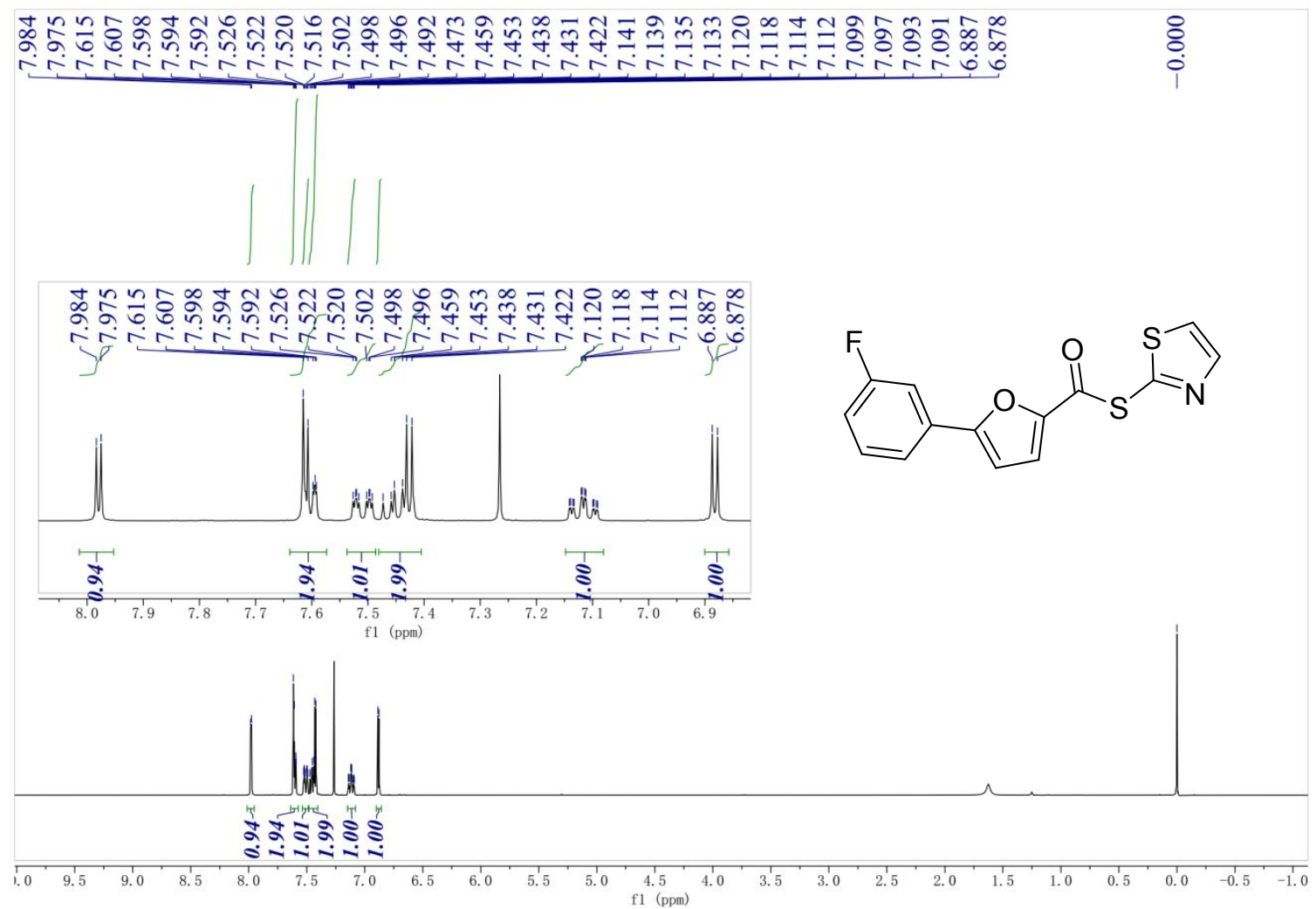

Figure S9 ${ }^{1} \mathrm{H}$ NMR spectrum of compound III-5 

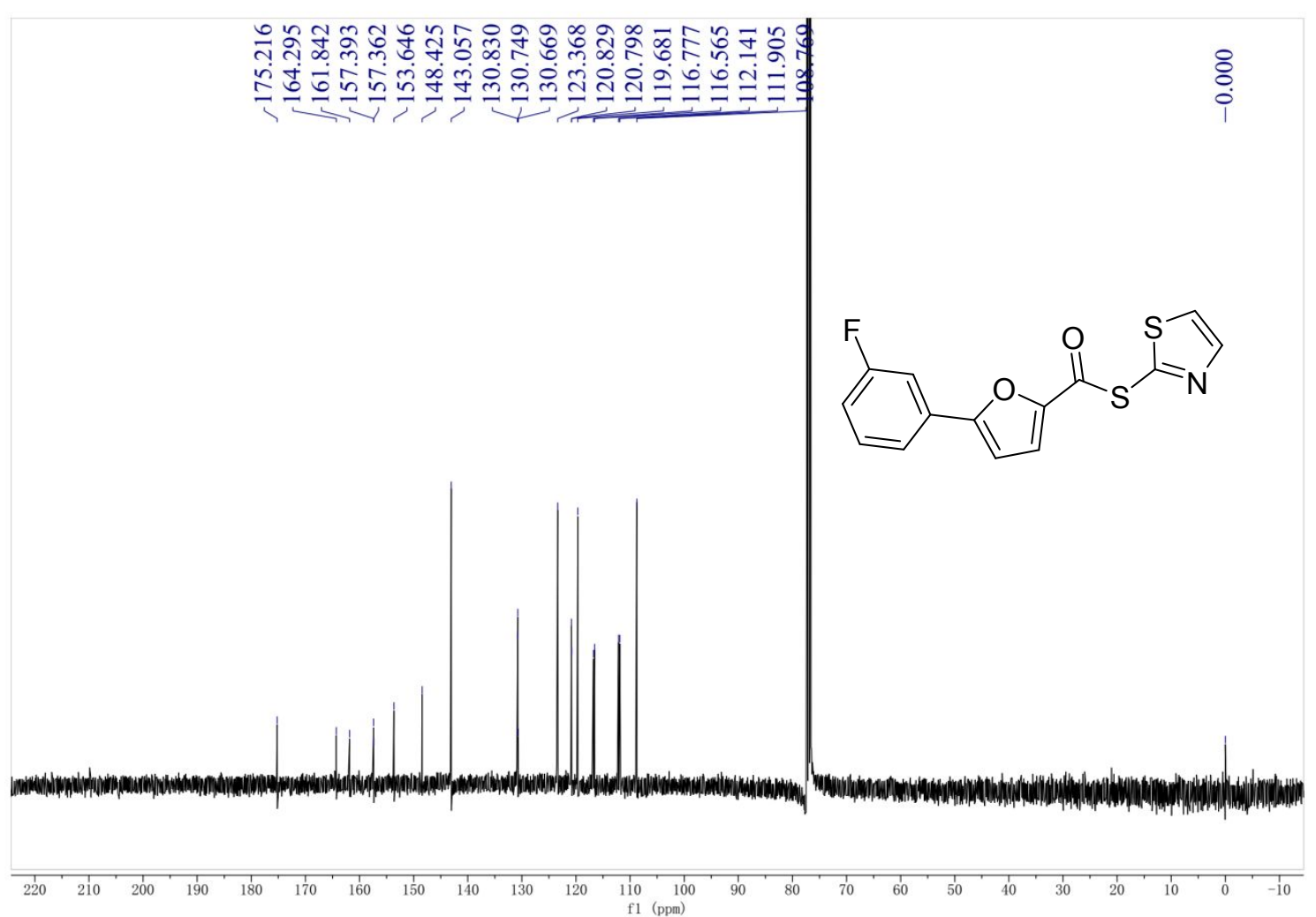

Figure S1- ${ }^{13} \mathrm{C}$ NMR spectrum of compound III-5

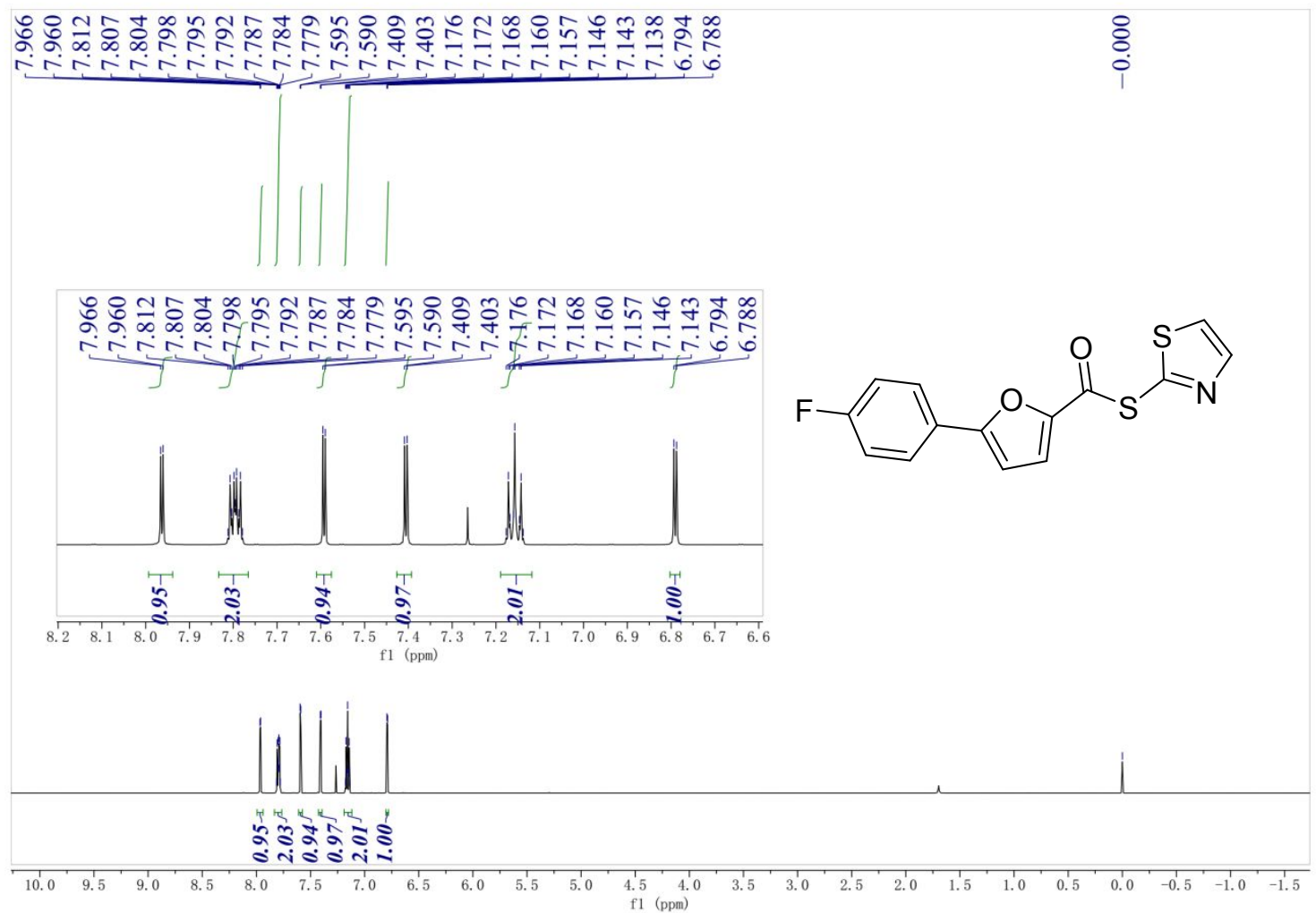

Figure S11 ${ }^{1} \mathrm{H}$ NMR spectrum of compound III-6 


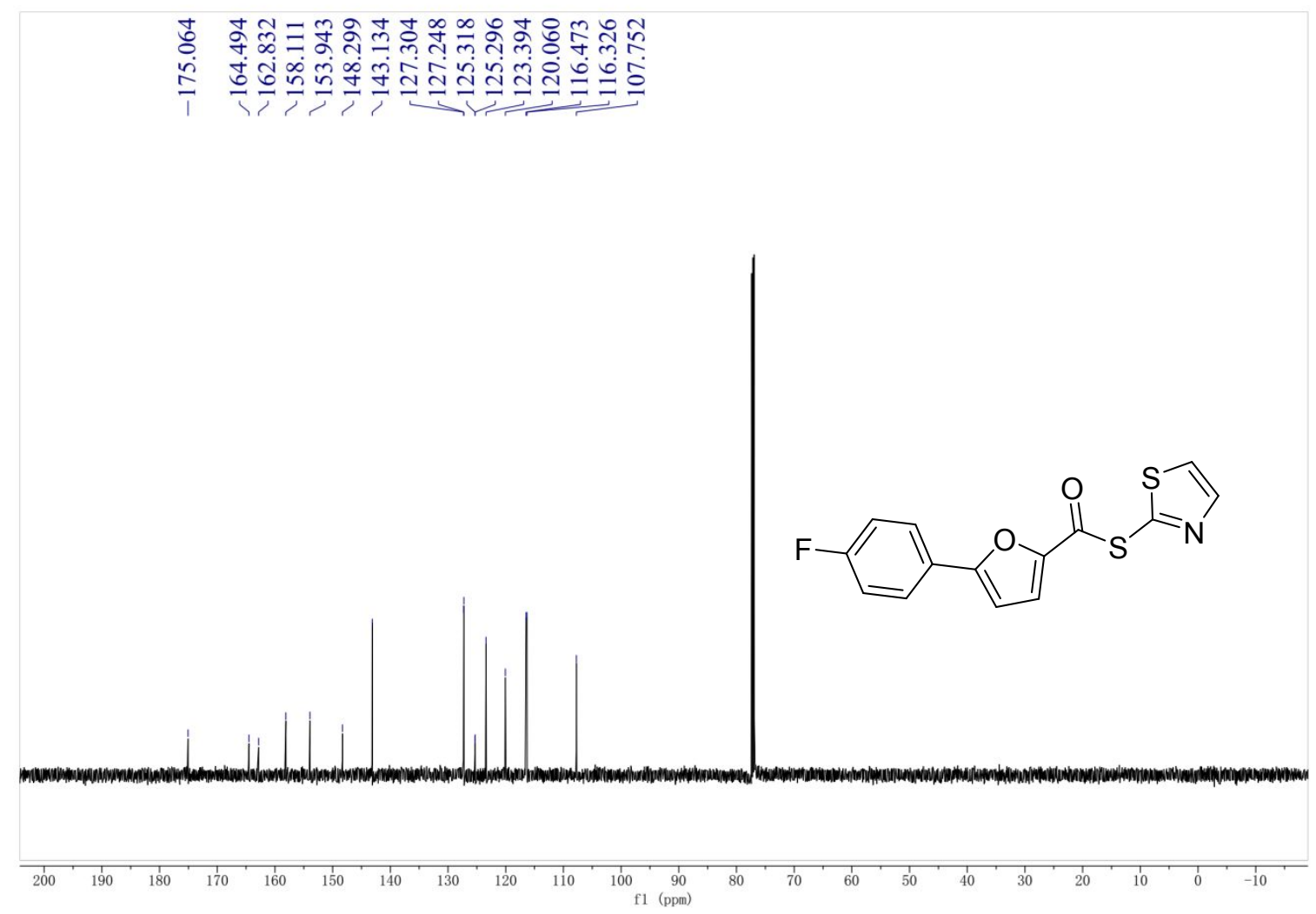

Figure S12 ${ }^{13} \mathrm{C}$ NMR spectrum of compound III-6

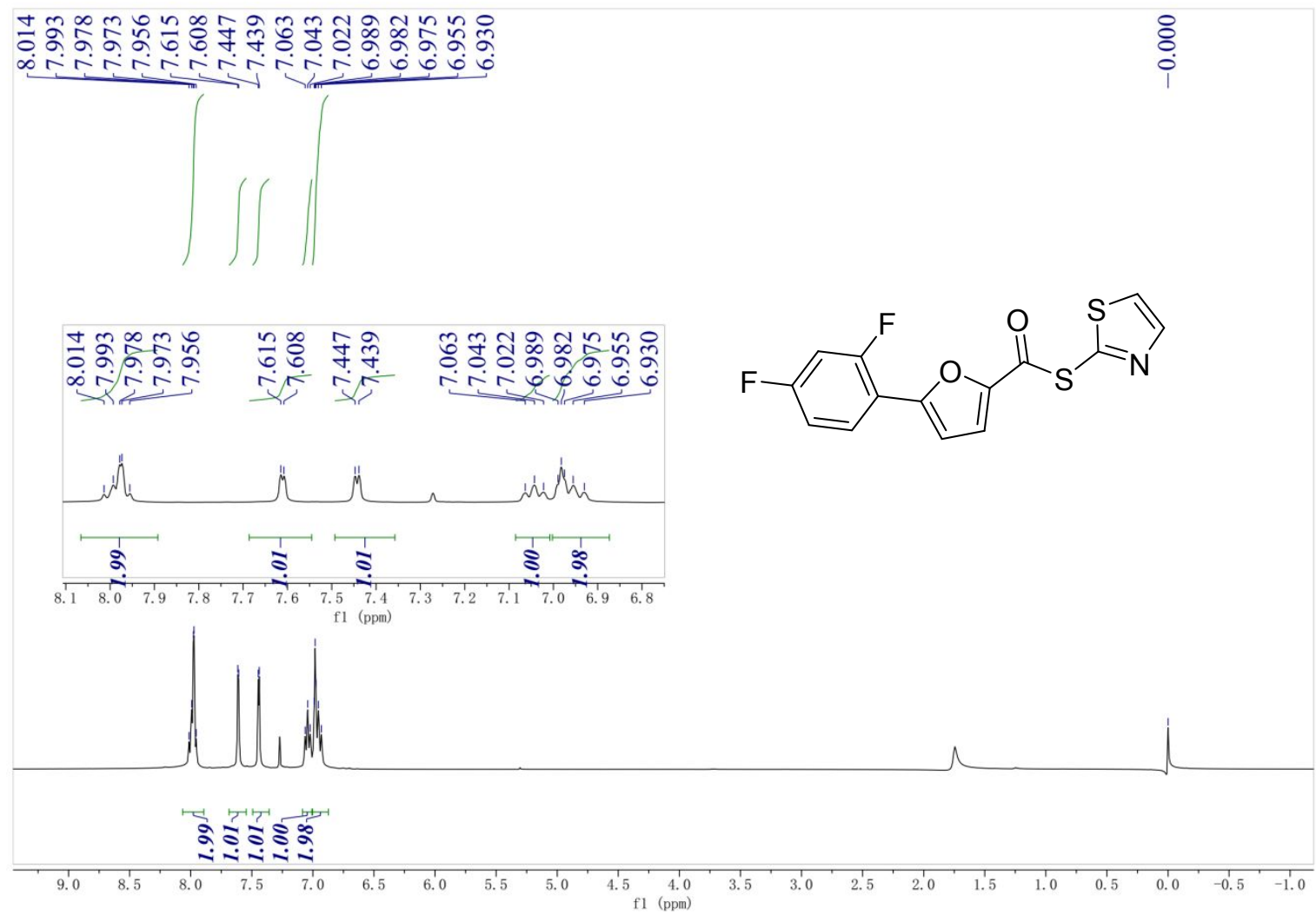

Figure S13 ${ }^{1} \mathrm{H}$ NMR spectrum of compound III-7 

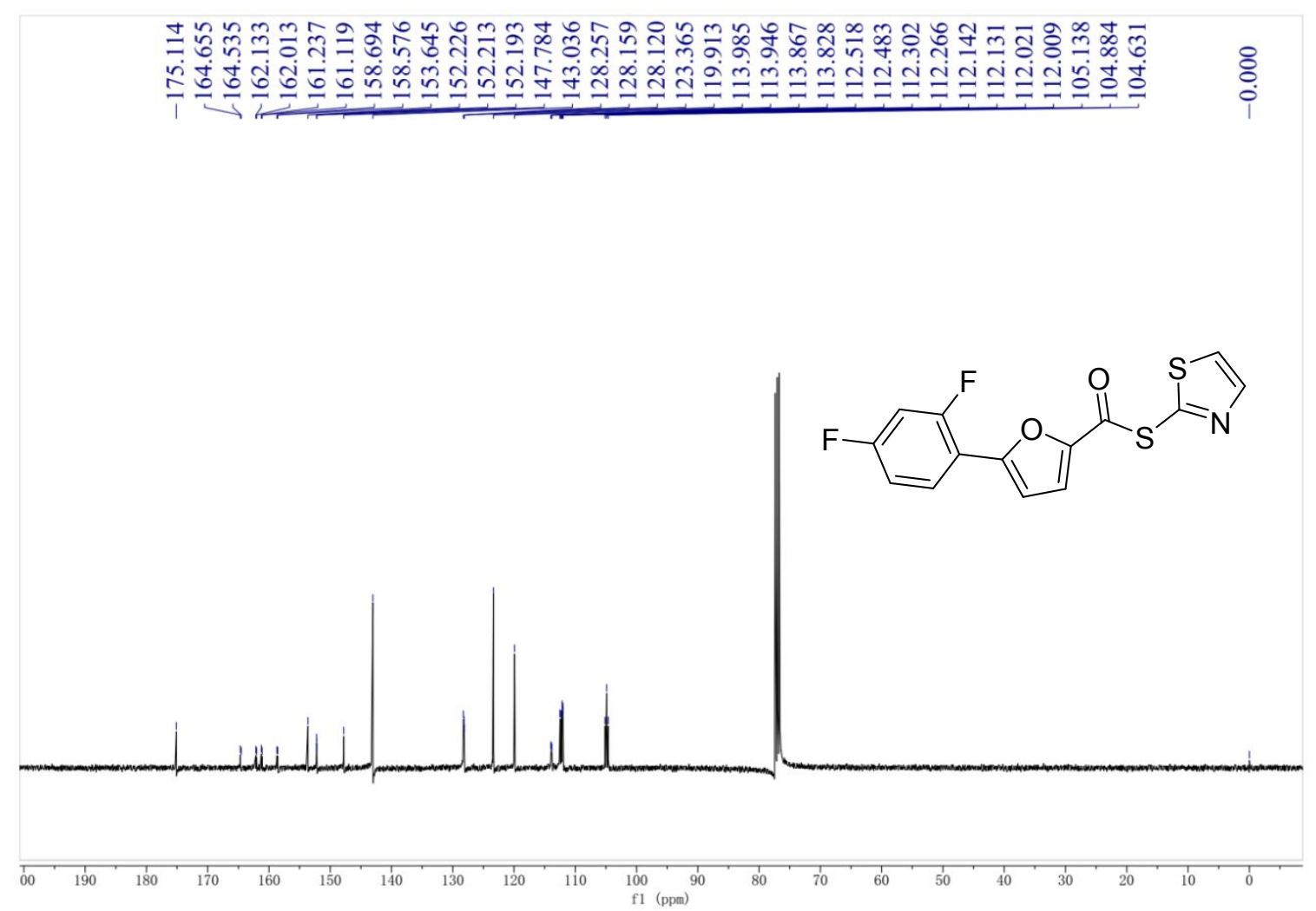

Figure S14 ${ }^{13} \mathrm{C}$ NMR spectrum of compound III-7

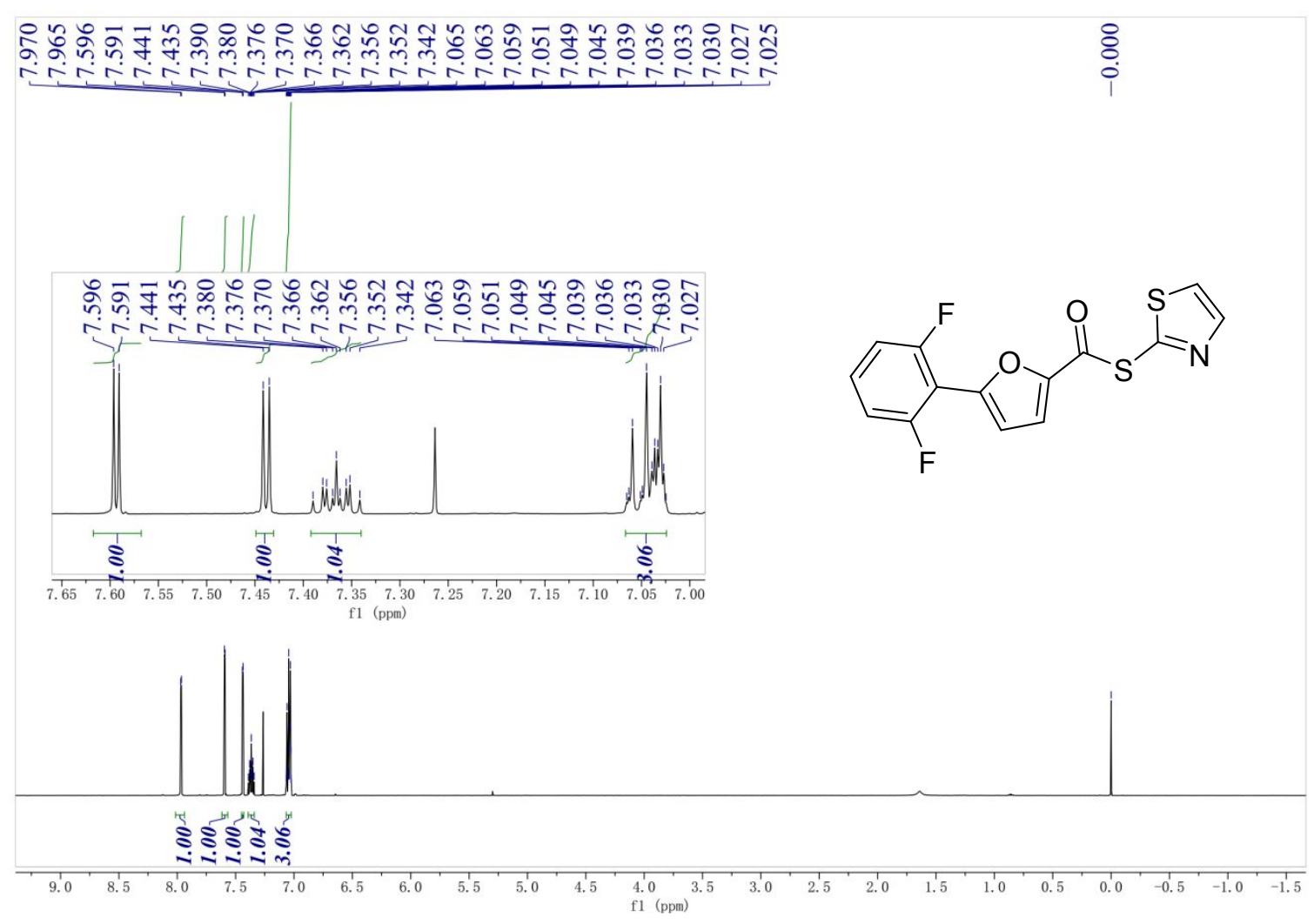

Figure S15 ${ }^{1} \mathrm{H}$ NMR spectrum of compound III-8 


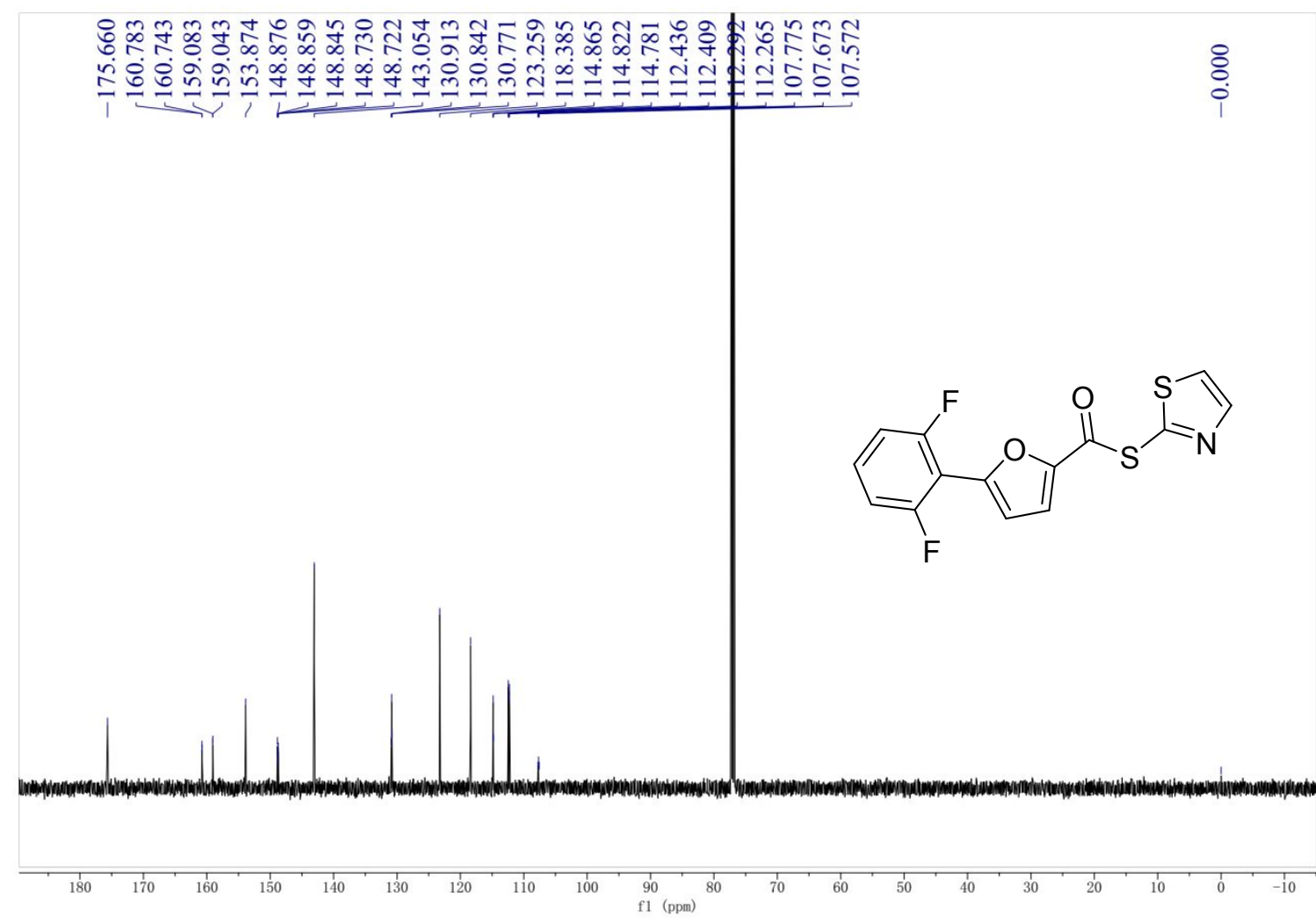

Figure S16 ${ }^{13} \mathrm{C}$ NMR spectrum of compound III-8

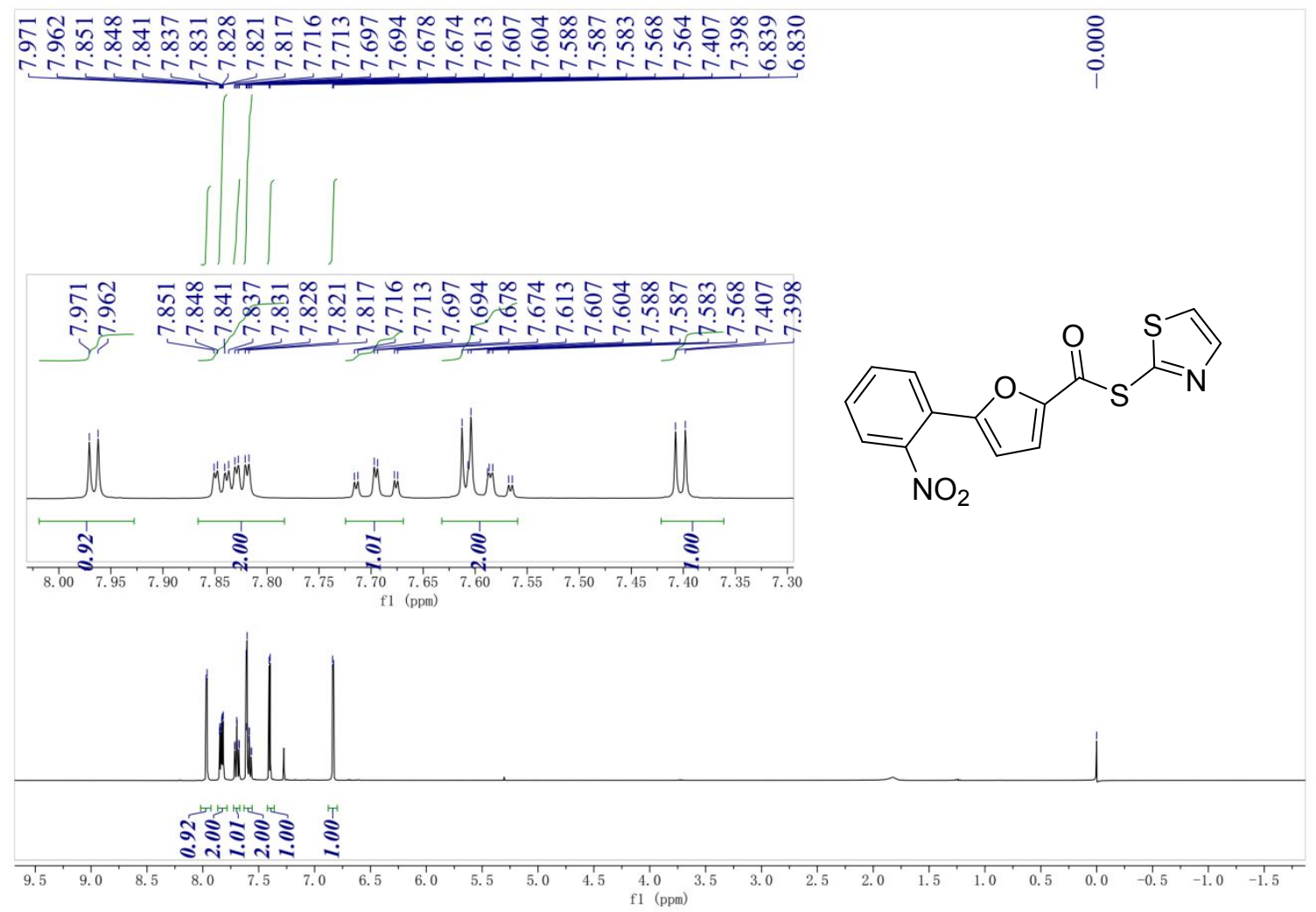

Figure S17 ${ }^{1} \mathrm{H}$ NMR spectrum of compound III-9 


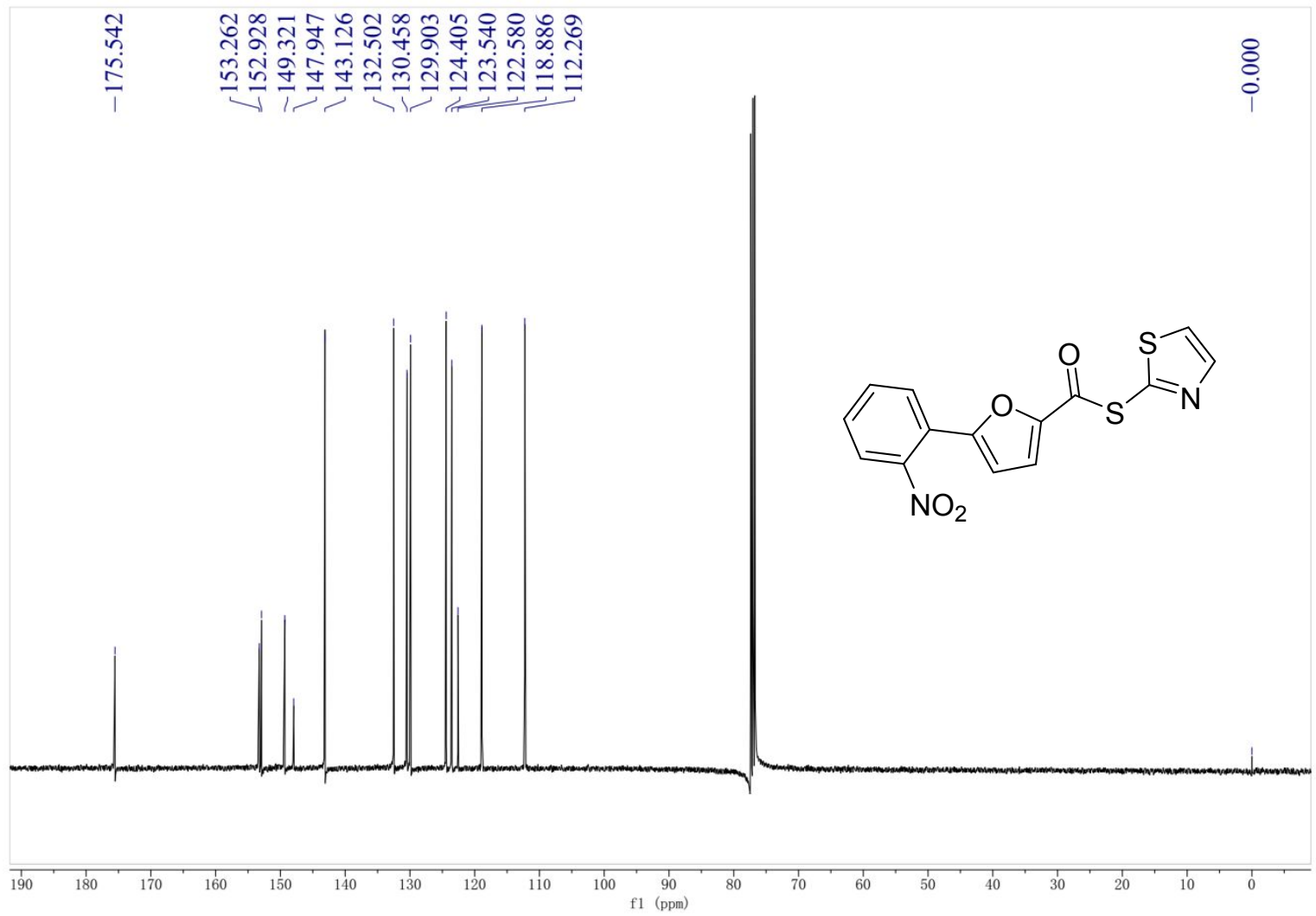

Figure S18 ${ }^{13} \mathrm{C}$ NMR spectrum of compound III-9

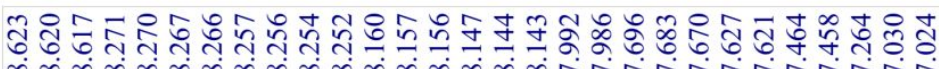

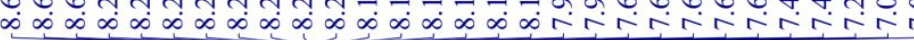

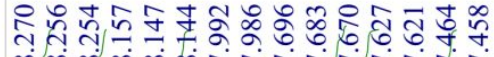
皮y

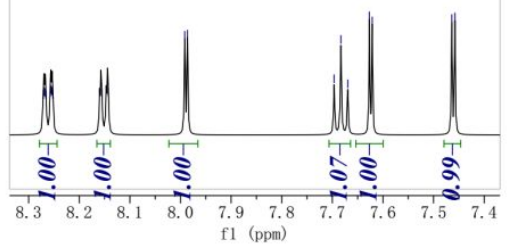<smiles>O=C(Sc1nccs1)c1ccc(-c2ccccc2[N+](=O)[O-])o1</smiles>

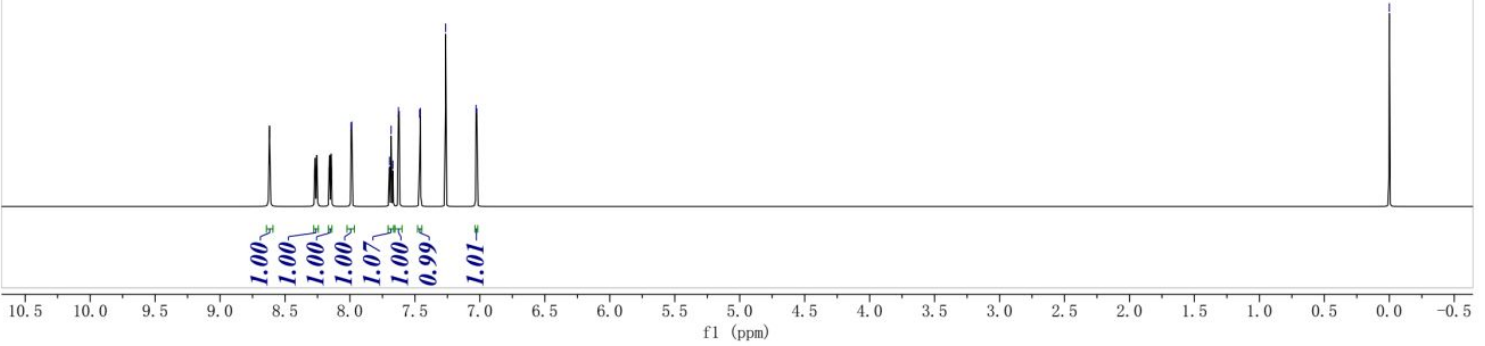

Figure S19 ${ }^{1} \mathrm{H}$ NMR spectrum of compound III-10 


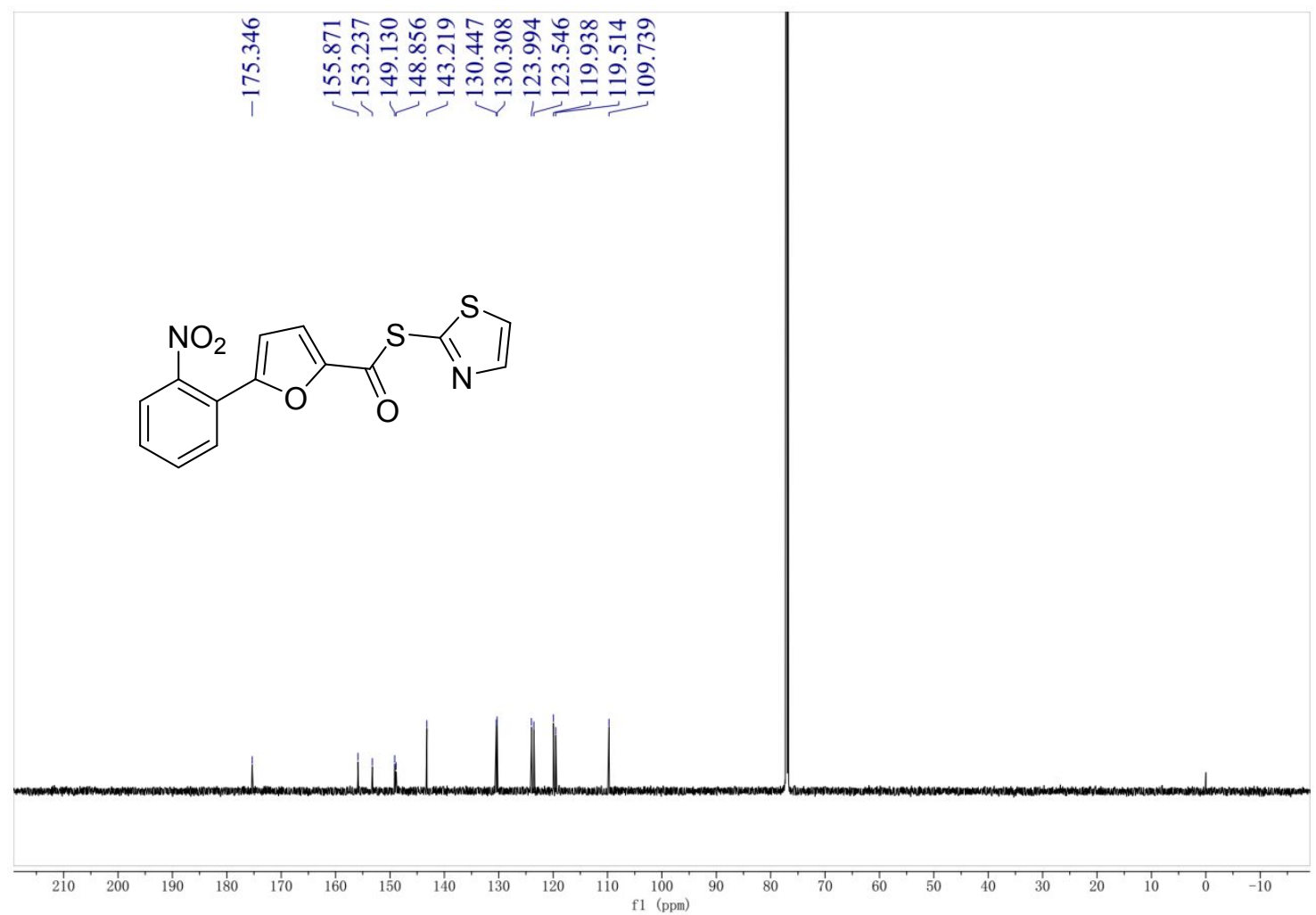

Figure S20 ${ }^{13} \mathrm{C}$ NMR spectrum of compound III-10

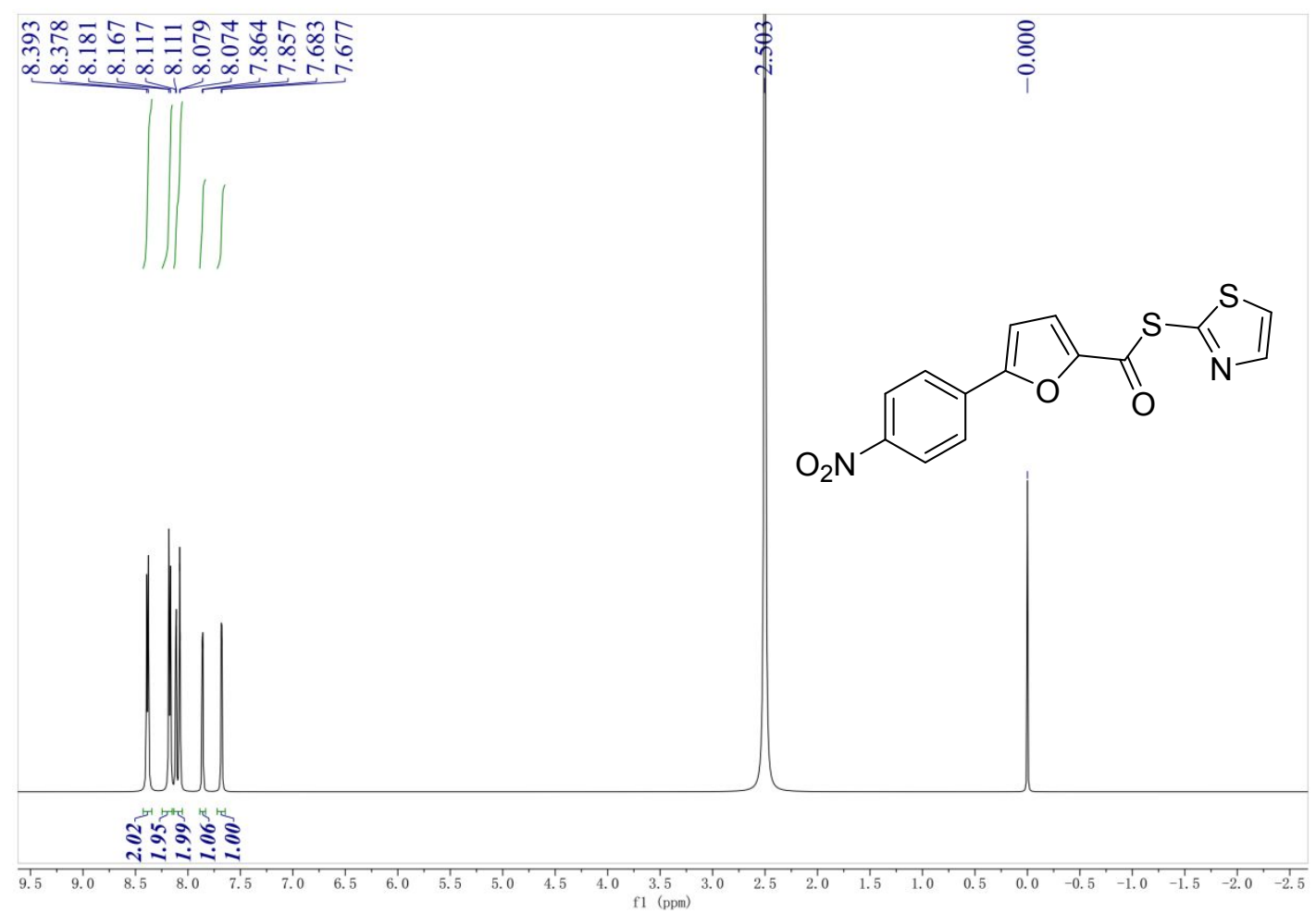

Figure S21 ${ }^{1} \mathrm{H}$ NMR spectrum of compound III-11 

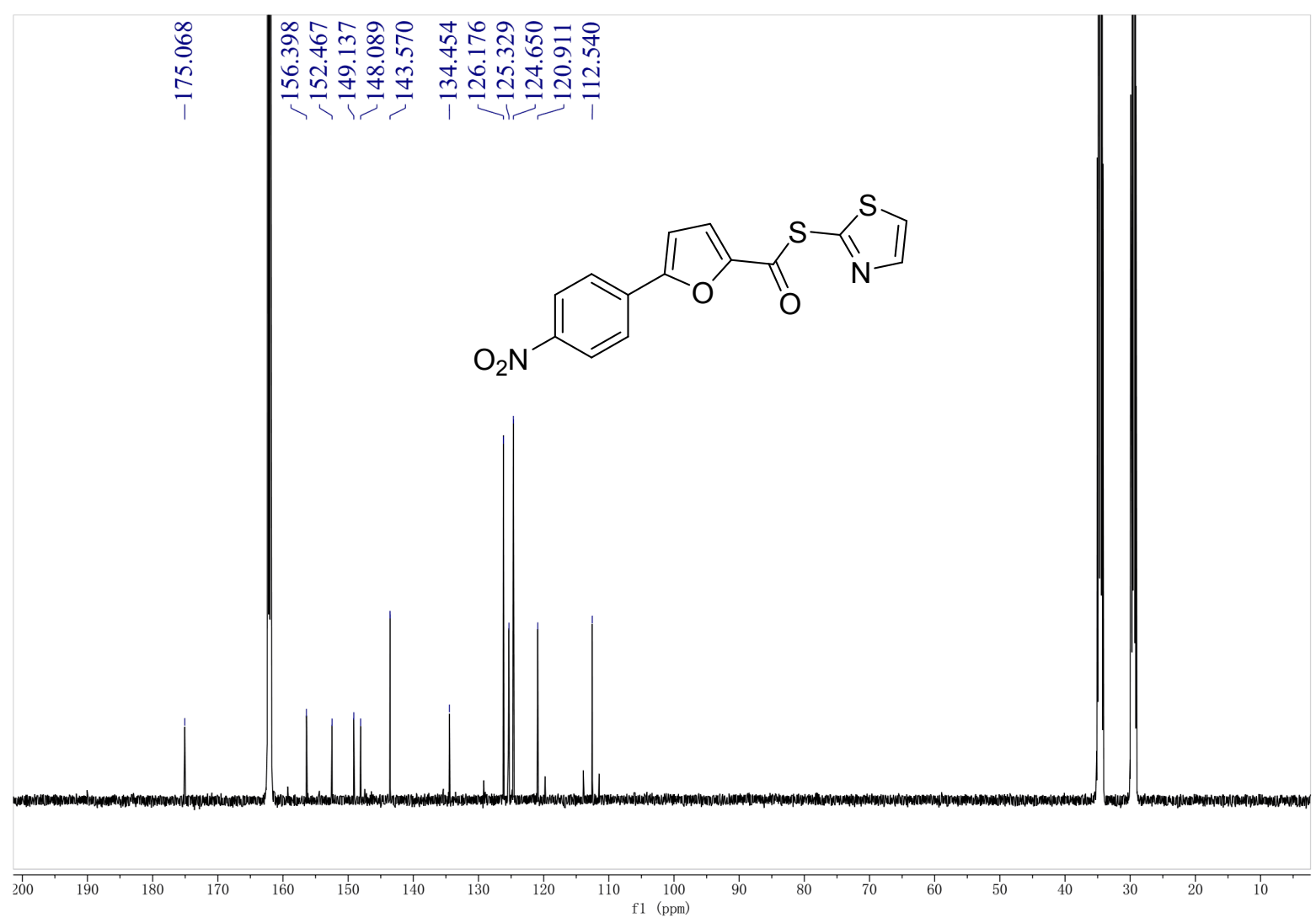

Figure S22 ${ }^{13} \mathrm{C}$ NMR spectrum of compound III-11

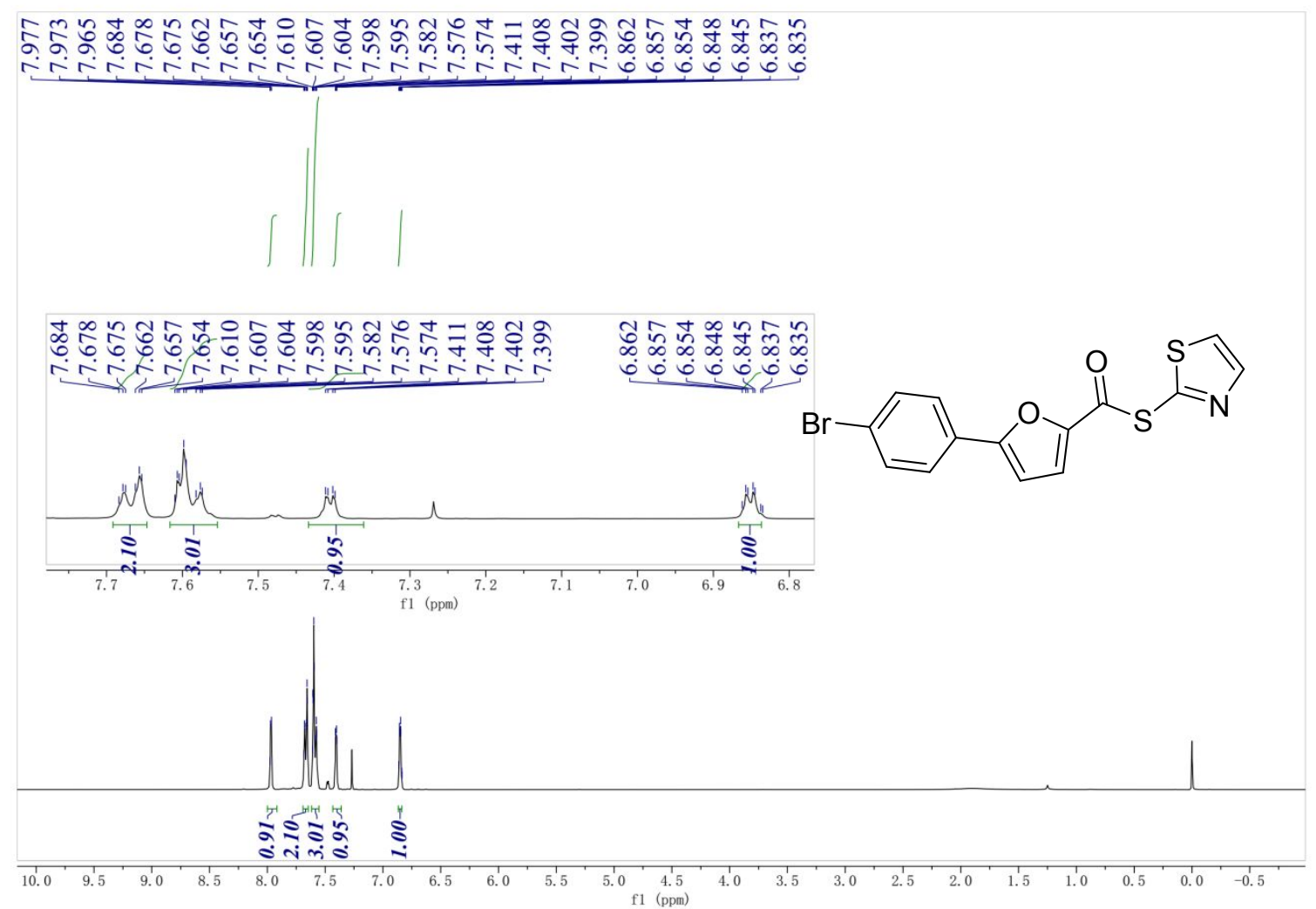

Figure S23 ${ }^{1} \mathrm{H}$ NMR spectrum of compound III-12 


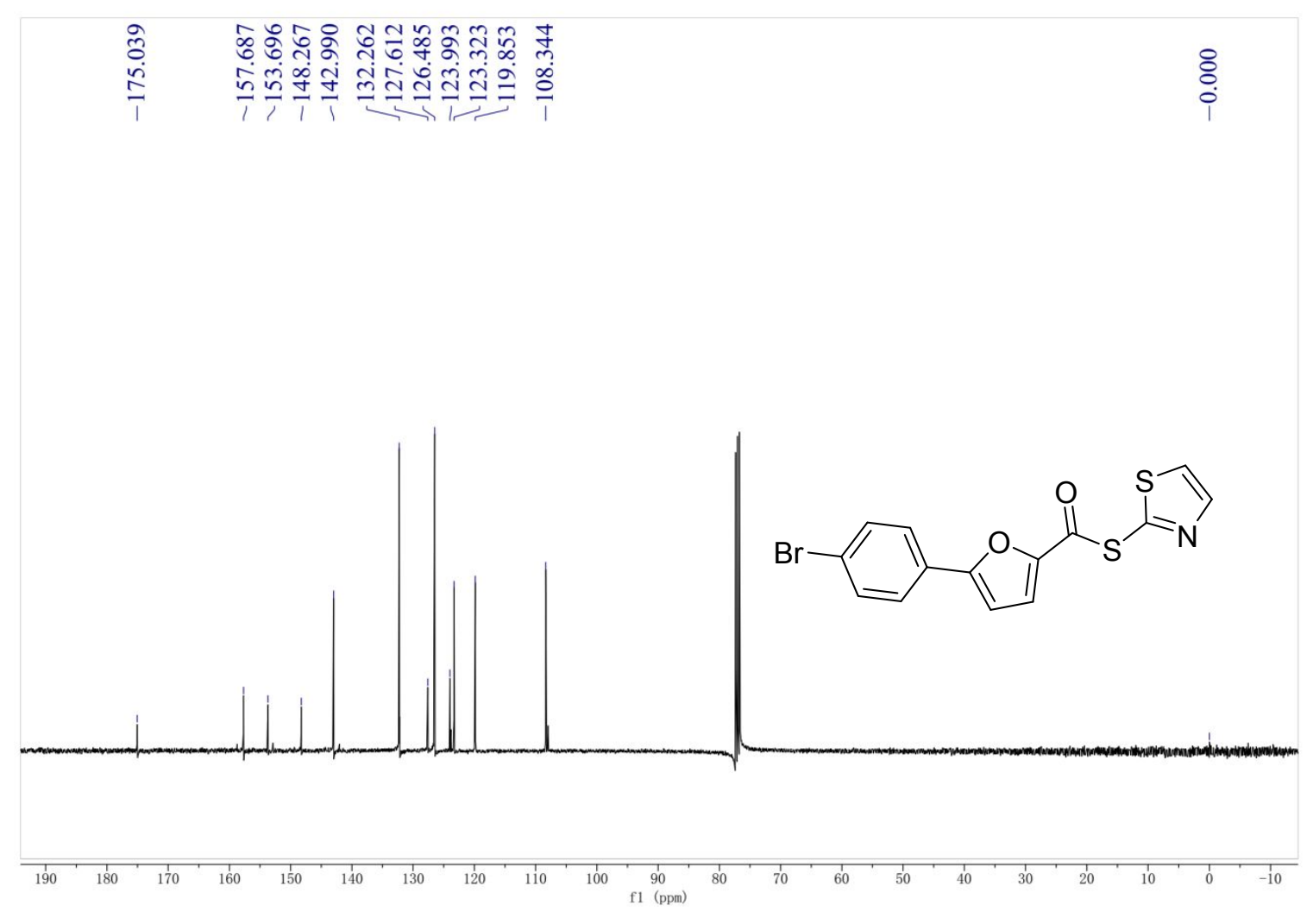

Figure S24 ${ }^{13} \mathrm{C}$ NMR spectrum of compound III-12

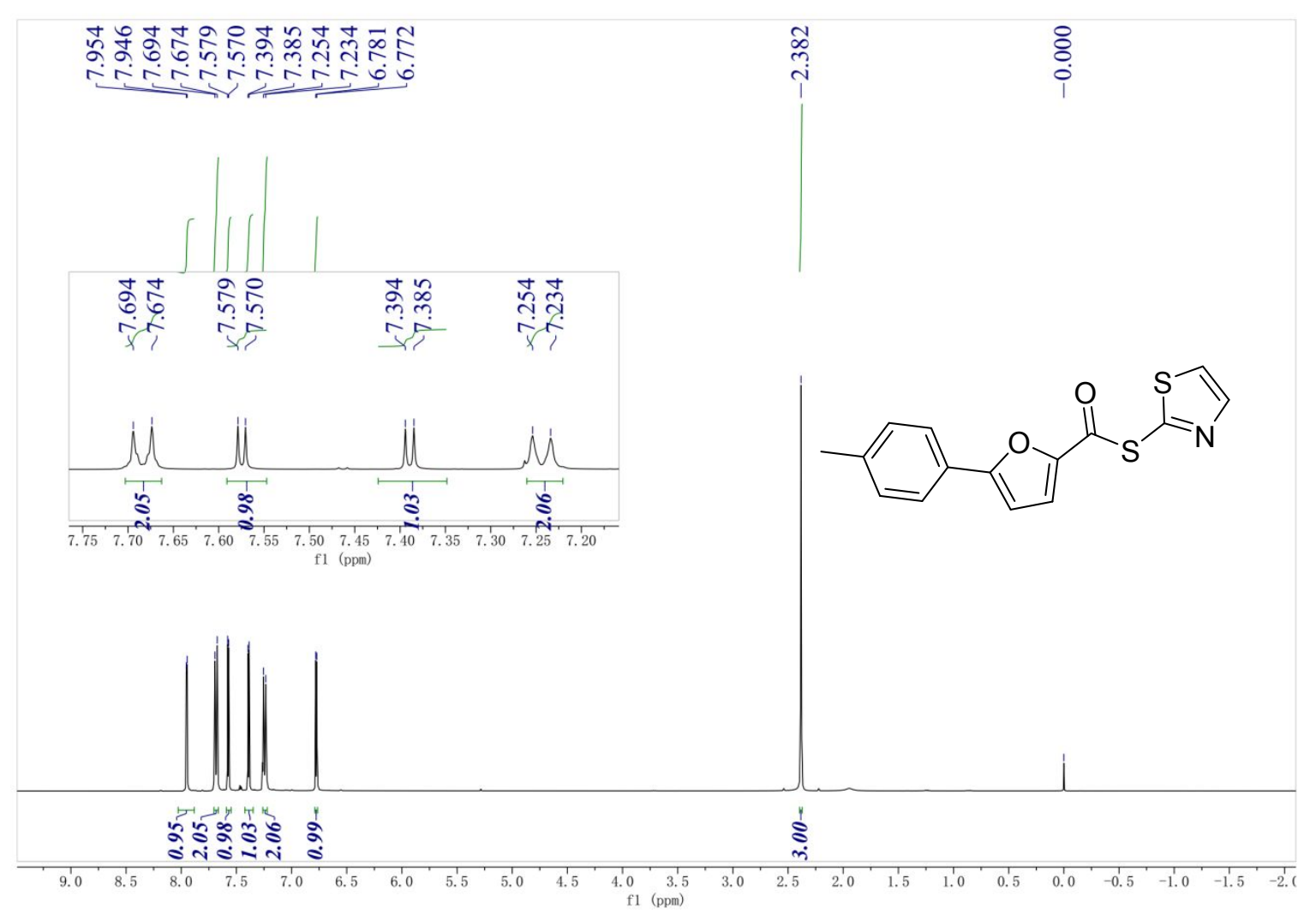

Figure S25 ${ }^{1} \mathrm{H}$ NMR spectrum of compoundIII-13 


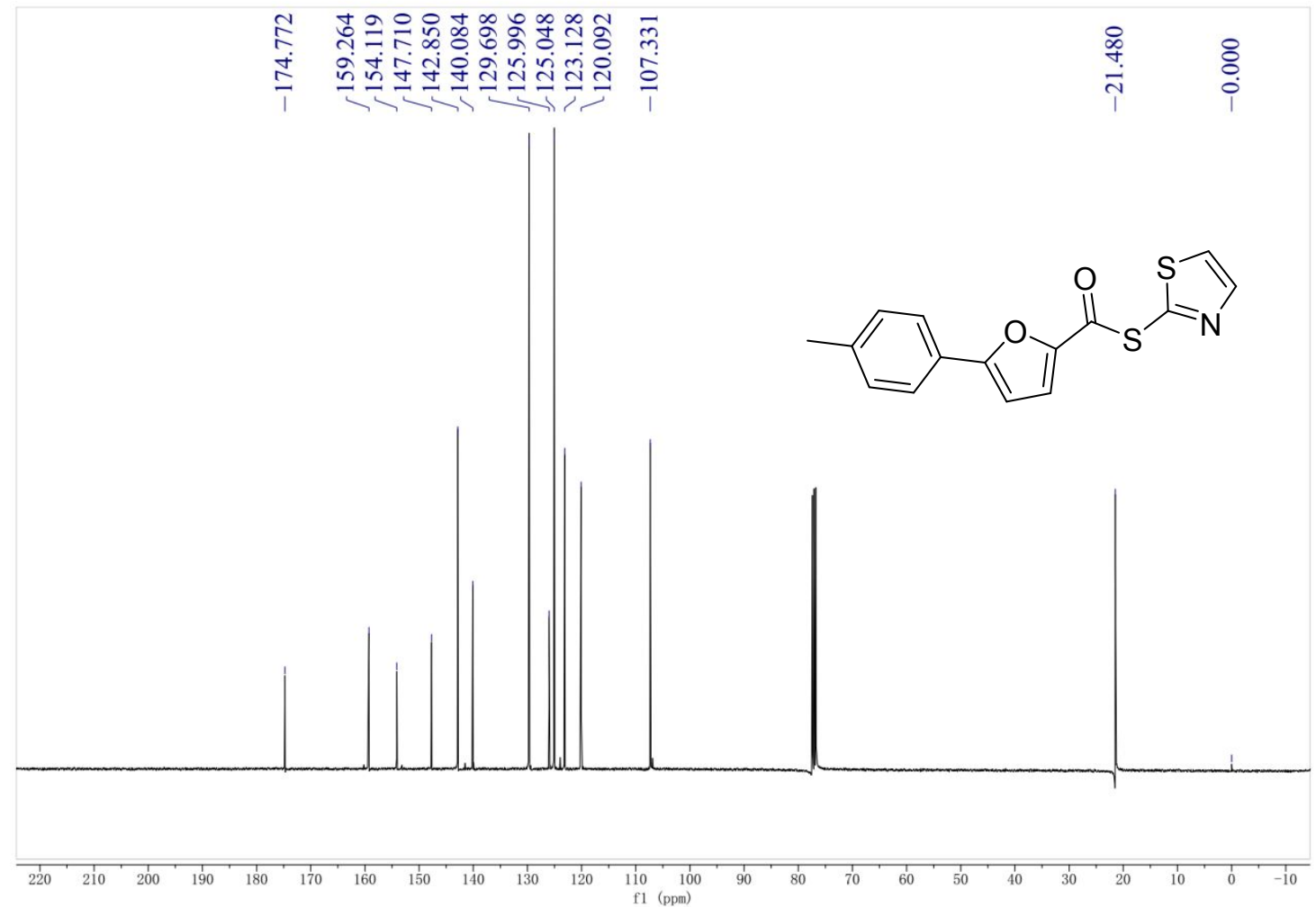

Figure S26 ${ }^{13} \mathrm{C}$ NMR spectrum of compound III-13

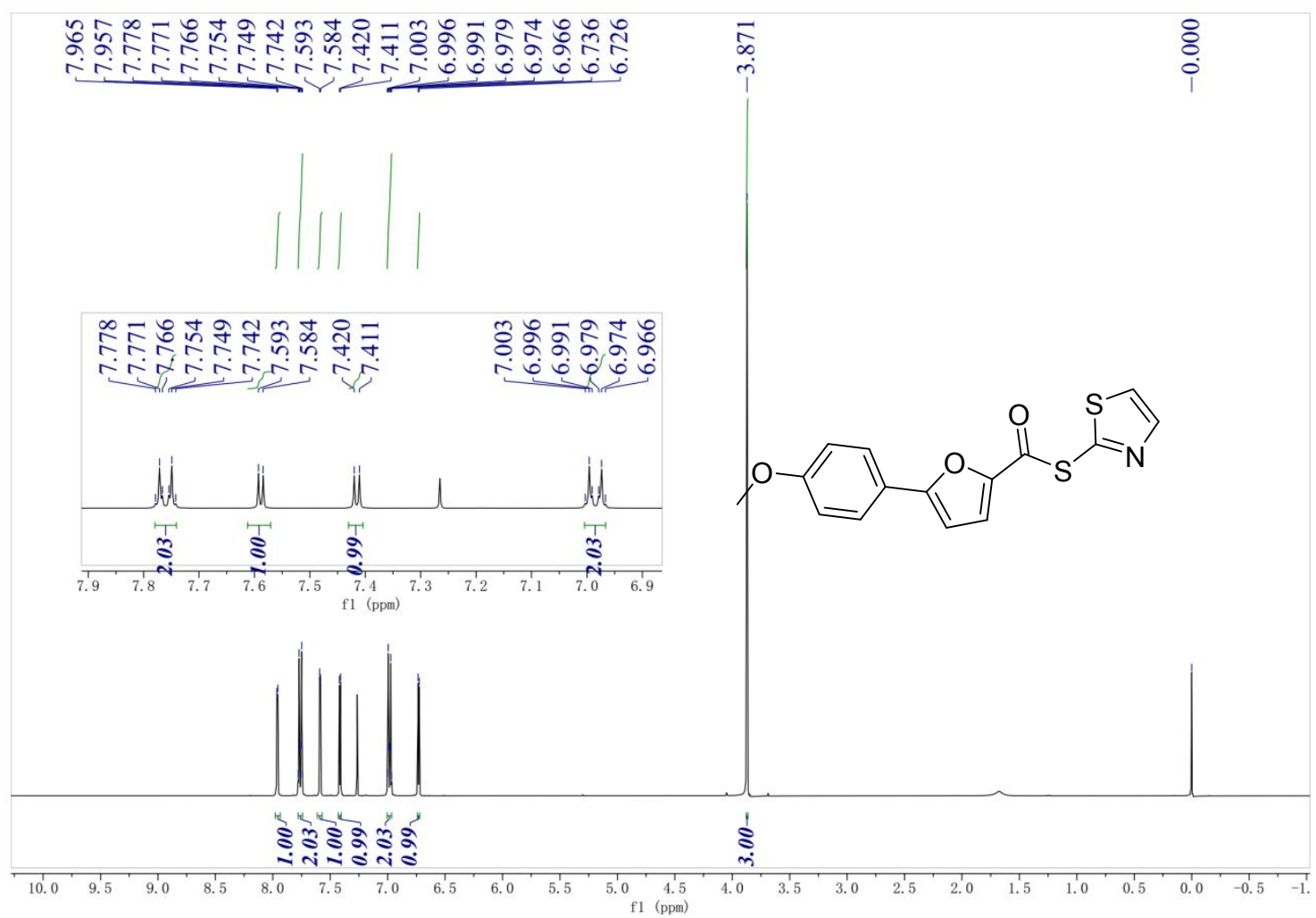

Figure S27 ${ }^{1} \mathrm{H}$ NMR spectrum of compoundIII-14 


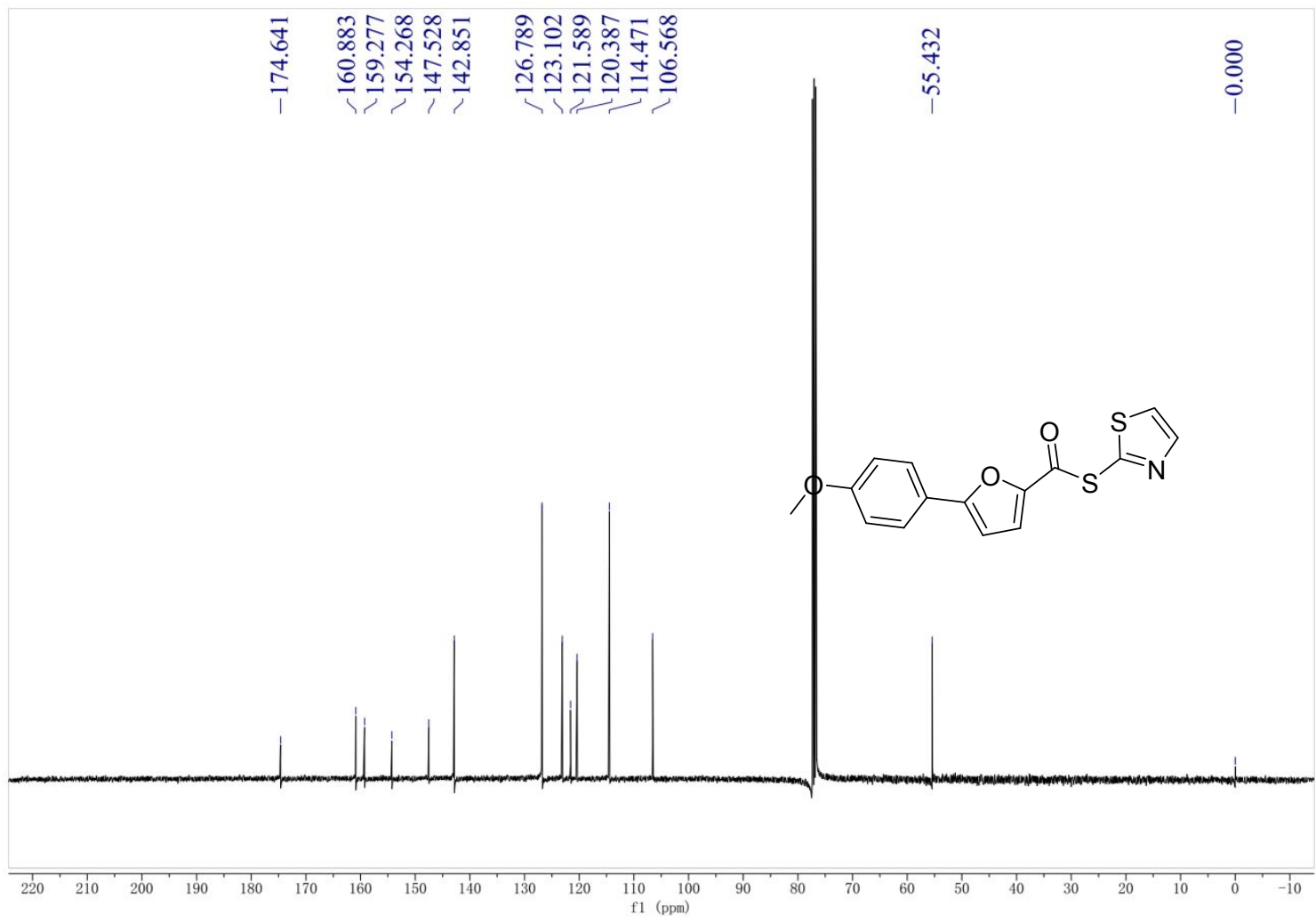

Figure S28 ${ }^{13} \mathrm{C}$ NMR spectrum of compound III-14

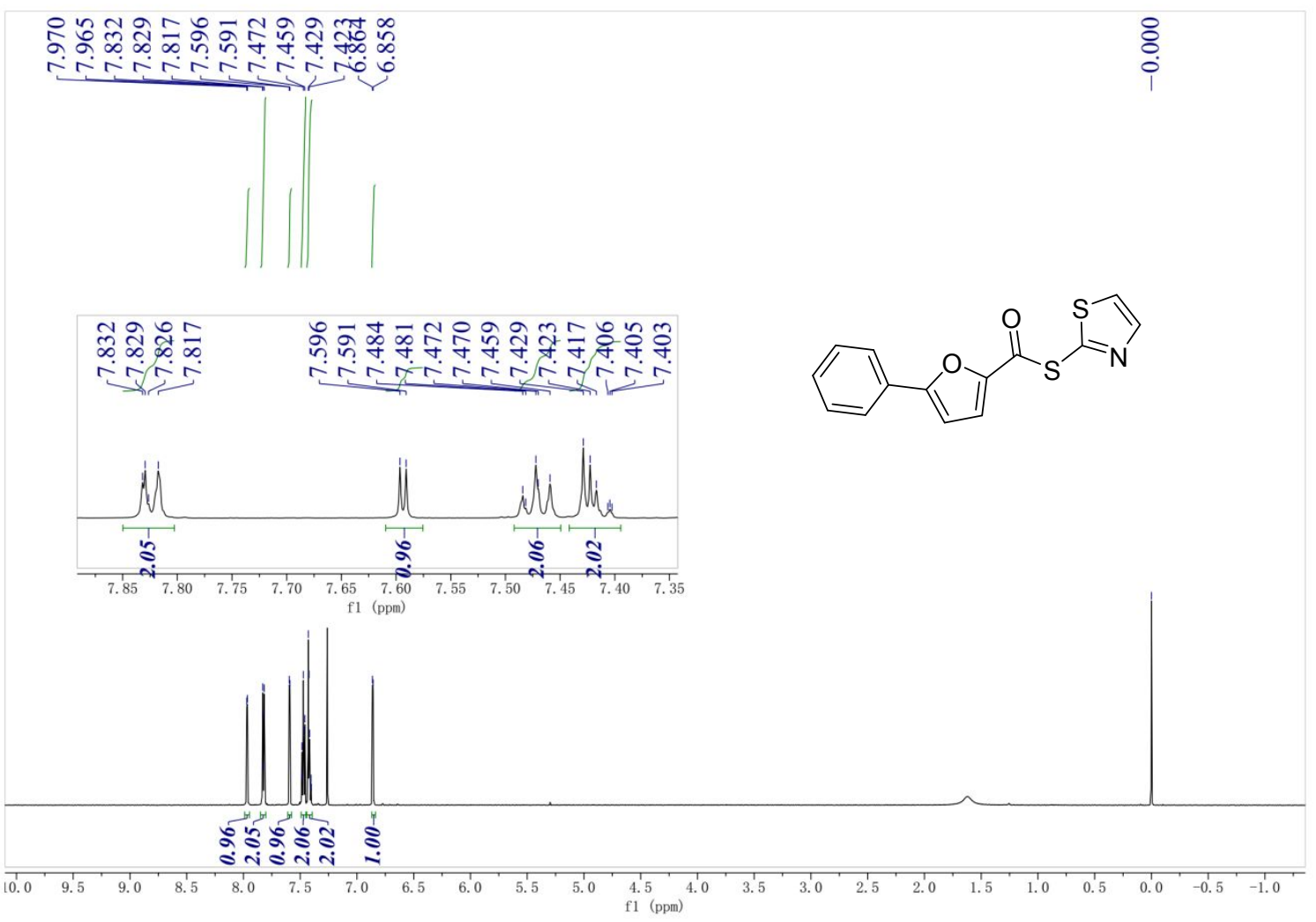

Figure S29 ${ }^{1} \mathrm{H}$ NMR spectrum of compound III-15 

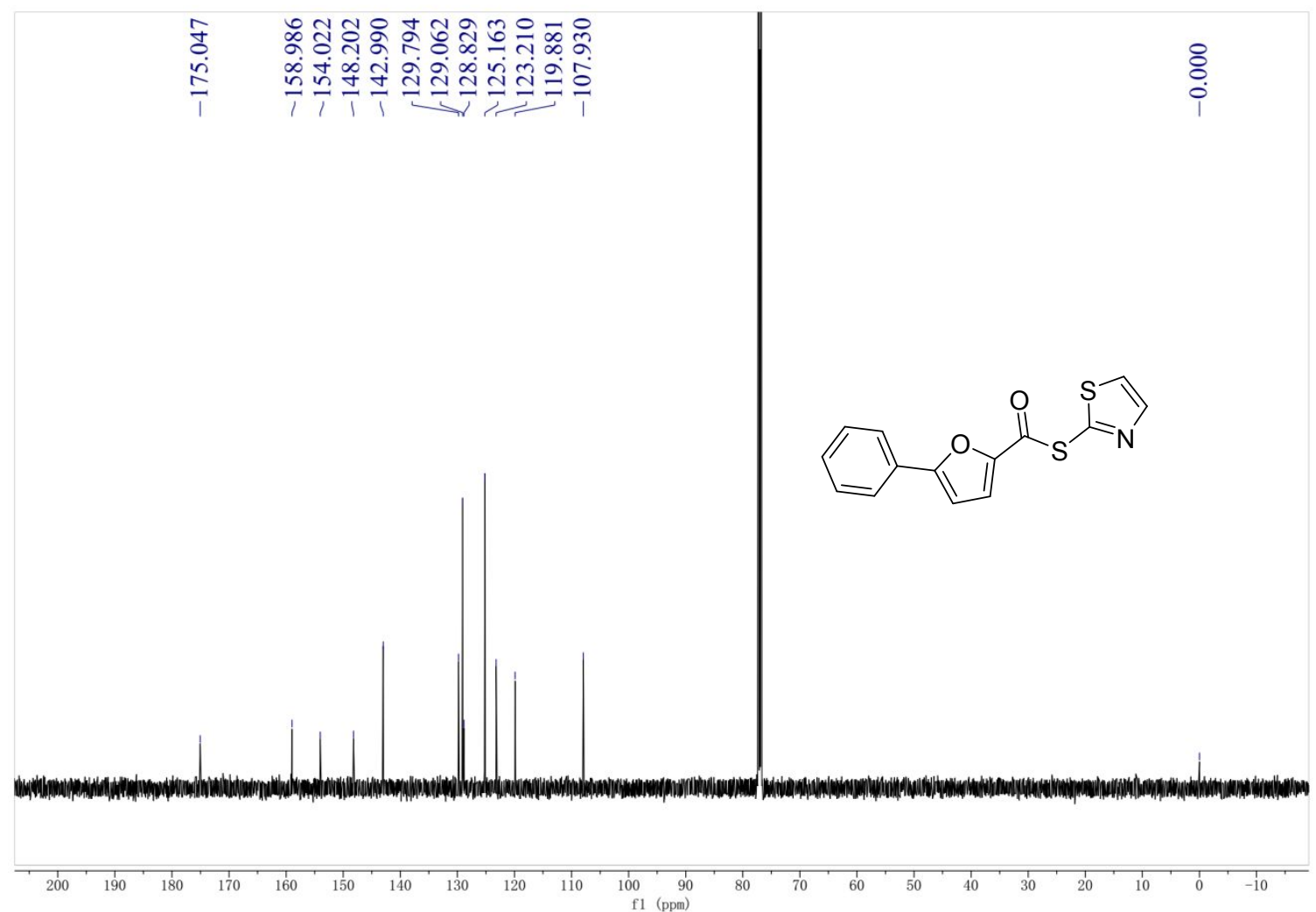

Figure S30 ${ }^{13} \mathrm{C}$ NMR spectrum of compound III-15 
Table S1. Strains plasmids and primers used in this study

\begin{tabular}{|c|c|c|}
\hline Strains, plasmids and primers & $\begin{array}{l}\text { Relevant } \\
\text { characteristics }\end{array}$ & Reference or source \\
\hline \multicolumn{3}{|l|}{ Strains } \\
\hline $\begin{array}{c}\text { Xanthomonas oryzae pv. } \\
\text { Oryzae PXO99A }\end{array}$ & $\begin{array}{c}\text { Wild-type strain, } \\
\text { Philippine race } 6, \mathrm{Cp}^{\mathrm{r}}\end{array}$ & Dr.Chenyang He \\
\hline \multicolumn{3}{|l|}{ Plasmids } \\
\hline pPROBE-AT & $\begin{array}{l}\text { Promoter-probe vector, } \\
\qquad \mathrm{Ap}^{\mathrm{r}}\end{array}$ & Lab collection \\
\hline pPhpal pProbe-AT in PXO99A & $\begin{array}{l}\text { Derivative with PCR } \\
\text { fragment containing } \\
\text { hpal promoter region, } \\
\text { Ap }^{\mathrm{r}}\end{array}$ & Dr.Chenyang He \\
\hline $\begin{array}{c}\text { pPhrpG pProbe-AT in } \\
\text { PXO99 }^{\mathrm{A}}\end{array}$ & $\begin{array}{c}\text { Derivative with PCR } \\
\text { fragment containing } \\
\text { hrpG promoter region, } \\
\text { Ap }^{\mathrm{r}}\end{array}$ & Dr.Chenyang $\mathrm{He}$ \\
\hline $\begin{array}{c}\text { pPhrpX pProbe-AT in } \\
\text { PXO99A }^{A}\end{array}$ & $\begin{array}{l}\text { Derivative with PCR } \\
\text { fragment containing } \\
h r p X \text { promoter region, } \\
\text { Ap }^{\mathrm{r}}\end{array}$ & Dr.Chenyang He \\
\hline $\begin{array}{c}\text { pPhrcT pProbe-AT in } \\
\text { PXO99A }\end{array}$ & $\begin{array}{c}\text { Derivative with PCR } \\
\text { fragment containing } \\
h r c T \text { promoter region, } \\
\text { Ap }^{\text {r }}\end{array}$ & Dr.Chenyang $\mathrm{He}$ \\
\hline
\end{tabular}

$\mathrm{Ap}^{\mathrm{r}}$, ampicillin resistance; $\mathrm{Cp}^{\mathrm{r}}$, cephalexin resistance 
Phpal-F

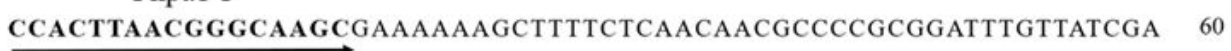

\begin{tabular}{|c|c|}
\hline $\begin{array}{c}\text { PIP-box } \\
\text { TTCTAAAACATTTTTTCACTTGCCCTCTTCGCGCGTACAAGCGCAATTTCGCAAAATTTC }\end{array}$ & 120 \\
\hline TGGCGATGATGGGCTTCCGCTTCTACTGTTTGATCGGGGCGCAAAACGCGCCTCGCAGCC & 180 \\
\hline $\begin{array}{l}\text { Phpal-R } \\
\text { ACCGCTGTCTAGGCACGGCTGTTGATACTAAAGACACATACCATTTAATCAGAGAGGAAT } \\
\text { Start codon }\end{array}$ & 240 \\
\hline CGTCACGATGAATTCTTTGAACACACAATTCGGCGGCAGCACGTCCAACCTTCAGGTTGG & 300 \\
\hline CCCAAGCCAGGACACAACGTTCGGTTCGAACCAGGGCGGCAACCAGGGCATCTCGGAAAA & 360 \\
\hline GCAACTGGACCAGTTGCTGTGCCAGCTCATCTCGGCCCTGCTTCAGTCGAGCAAAAATGC & 420 \\
\hline TGAGGAGGGTAAGGGTCAGGGTGGCGATAATGGCGGTGGCCAGGGCGGCAATTCGCAGCA & 480 \\
\hline GGCTGGGCAGCAGAATGGCCCCTCGCCATTCACCCAGATGCTGATGCATATCGTCGGAGA & 540 \\
\hline GATTCTCCAGGCGCAGAATGGTGGTGGTGCTGGTGGCGGCGGGTTCGGCGGCGGGTTCGG & 600 \\
\hline $\begin{array}{l}\text { CGGTGACTTTAGTGGCGACCTCGGCCTCGGCACCAACCTCTCGAGCGACAGCGCATCGAT } \\
\text { Stop codon }\end{array}$ & 660 \\
\hline GCAGTAA & 667 \\
\hline
\end{tabular}

Figure S31. DNA sequence of Xoo hpal gene and its promoter region. Sequences for a PIP box, start codon, stop codon and the primers used for amplification of the promoter region are indicated as bold fonts. 
A pxog9a phpal.seg RS105 Phpal.seq Consensus

PX099A_Phpa1.seg RS105_Phpa1.seq Consensus

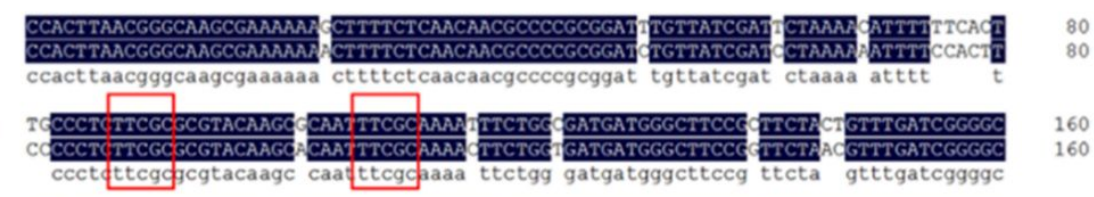

PX099A Phpa1.seq RS105_Phpal.seq Consensus

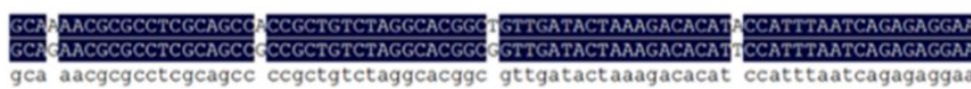

PX099A Phpal.se

RS105 Phpal.seq

Consensus

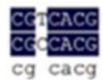

B

PX099A_PhrpB RS105_PhrpB

Consensus

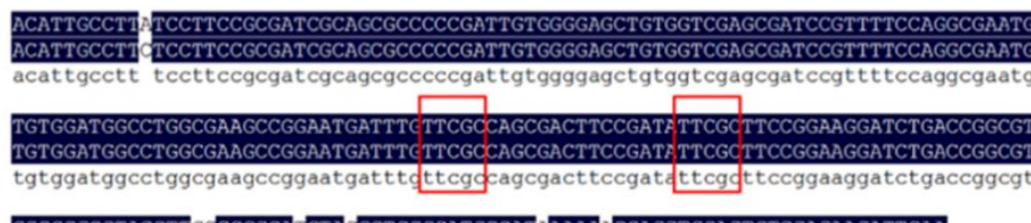

PX099A Phrp

RS105 PhrpB

Consensus

PX099A_PhrpB
RS105 $\overline{P h r p B}$

RS105_PhrpB

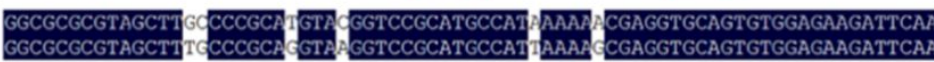

ggcgegcgtagctt cccgca gta ggtccgcatgccat aaaa cgaggtgcagtgtggagaagattca

\section{0}

240

Figure S32. Sequence alignment of promoter regions of $h p a l$ (A), $h r c T$ (B) between Xoo 